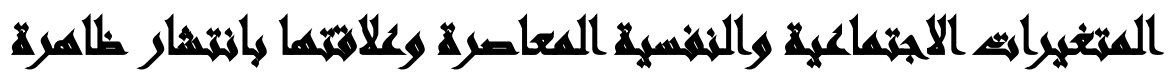

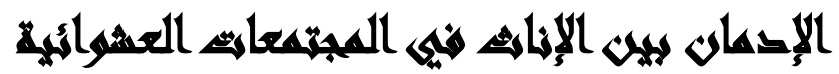 \\ [1T]
}

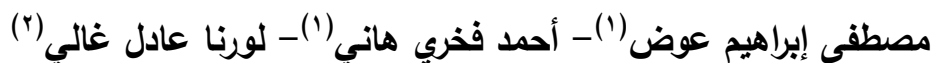

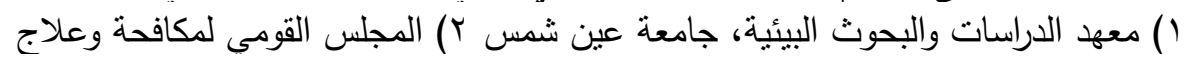

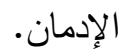

\section{المستخلس}

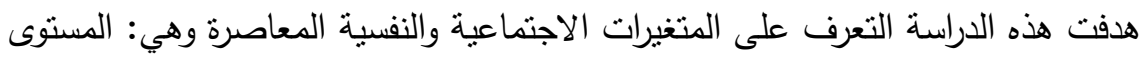

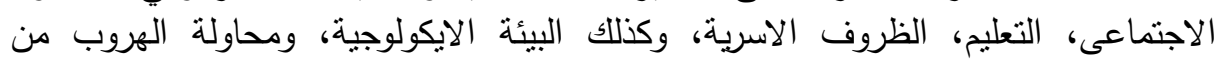

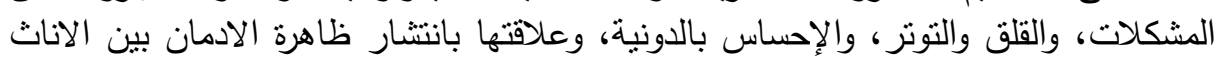

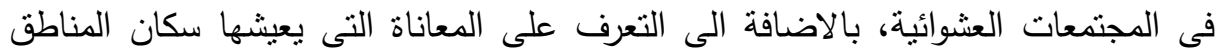

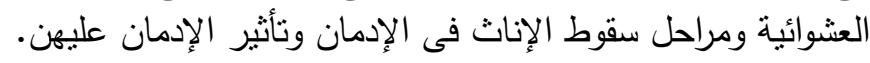

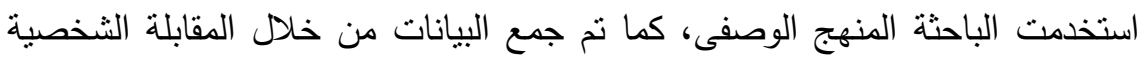

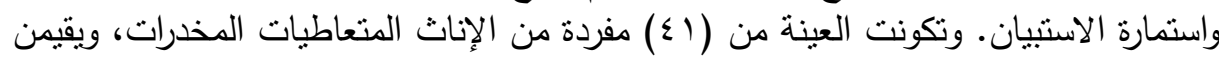

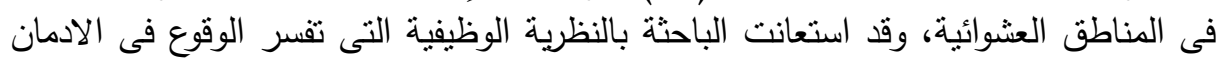

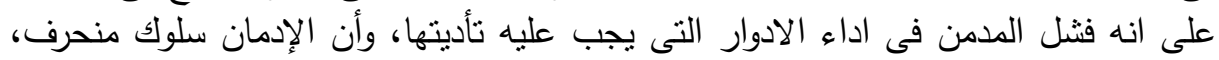

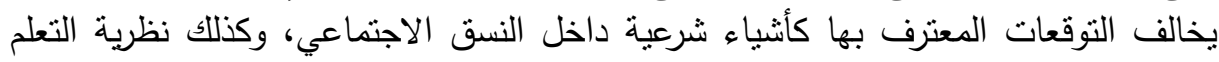

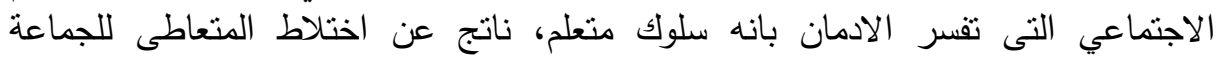

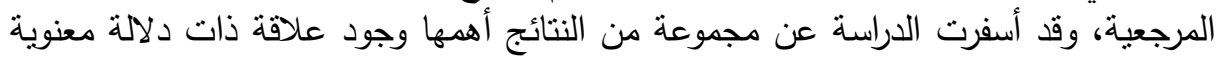

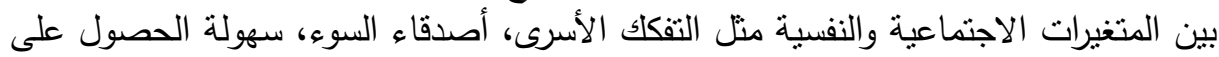

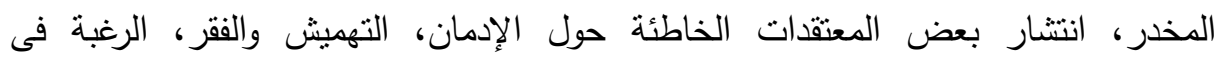

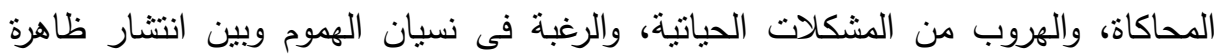

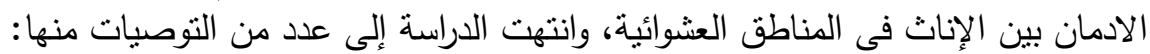

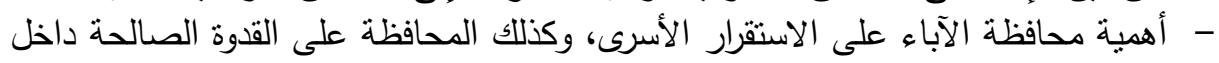

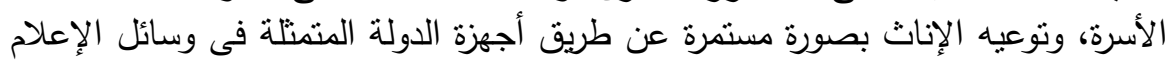

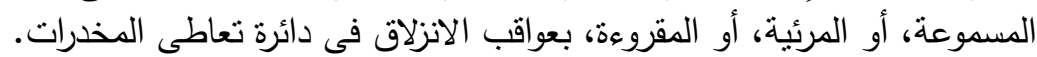

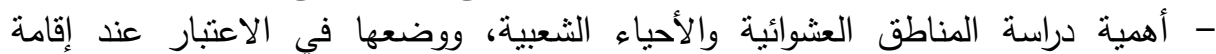

$$
\text { المشاريع فى الدولة. }
$$




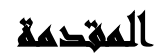

تعد مشـكلة الإدمـان والتعـاطى مـن أهم المشكلات التـى تشـغل الـول جميعها سـواء المتقدمة منها، أو النامية، لأنها ترتبط باقتصاديات هذه الدول؛ لذادئ اهن حاولت الدان الدراسات والأبحاث

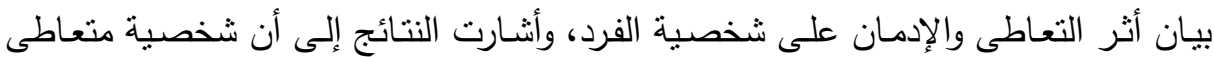
المخدرات من الثخصبات غير السويه، والتى تتخفض كفاءتها الثخصية والاجتماعية'. لم تتكون هذه الثخصية المدمنـة إلا بتأثير المتغيرات الاجتماعيـة والنفسية، العوامل لـل البيئية، والوسط الذى يعيش، ينمو ، ويتفاعل فيه الفرد، ويؤثر بوضوح فى تتكيل شخصيته ونموها. كما تؤثز المواقف الضاغطة المصحوبة بالفشل على الفرد؛ فتضعف قدرته التوافقيه،

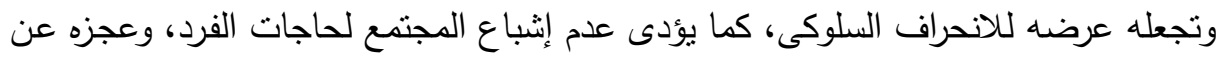

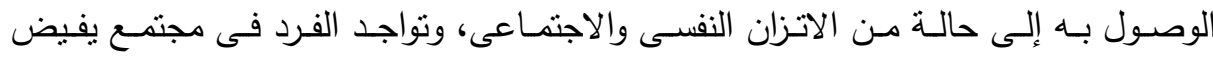
بالحرمان، والإحباط، وعدم الأمن، والتنافس الثديد بين الناس، وعدم المساواة إلى ندو سلوك الكى

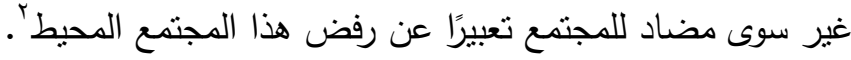
ييرز فى خضم هذه المشكلة الخطيرة تزايد حجم تعاطى المخدرات بين الإناث فى الآونة الأخيرة فى الوقت الذى تمنل فيه المرأة نصف الطاقة البشرية الموجودة فى المجتمع، وأصبح

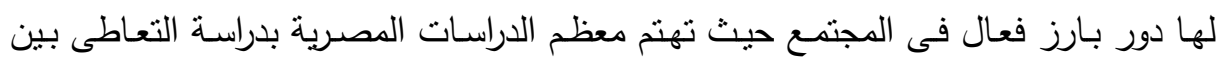
الذكور، وذللك على اعتبار أنه أكثر انتشارًا بينهم، وهذا الاعتبار أن كان صحيحًا فلا يعد كافيًا

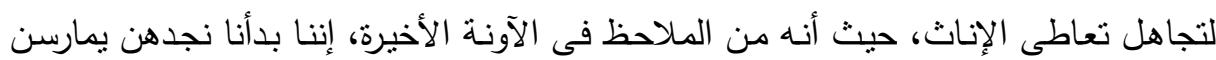

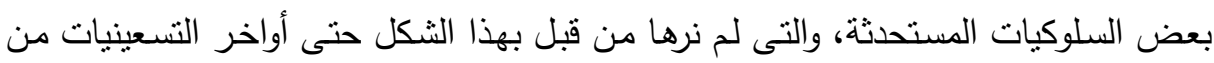
القرن الماضـى مثلل: الجلوس على المقاهى، وشرب الثيشـة، وتدخين السجائر على المـلأ،

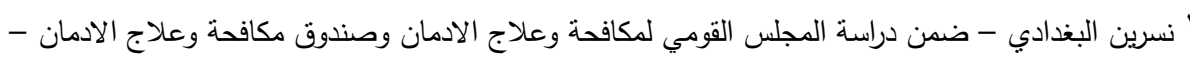

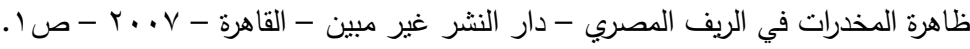

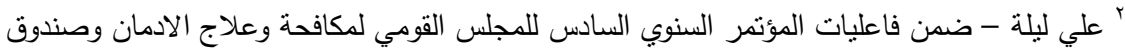

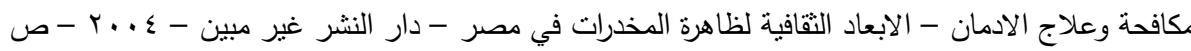


وغير ذلك؛ لذا أجريت هذه الدراسـة على الإنـاث فقط للتعرف على المتغيرات الاجتماعيـة والنفسية المعاصرة وعلاقتها بانتثار ظاهرة إدمان الإناث فى المجتمعات العشوائية.

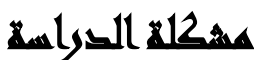

مما لا شك فيه أن قضية المخدرات أصبحت تمثل اليوم خطرًا داهمًا يهدد كيان بل وإمكانيـة تقدم وتتميـة أى مجتمع، ويــرك المـره حـدة وخطـورة هـذه المشـكلة الاجتماعيـة والاقتصادية بل والسياسية وحجم الخسارة التى تعود على المجتمع.

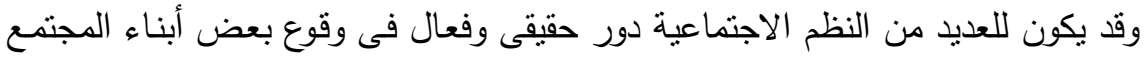

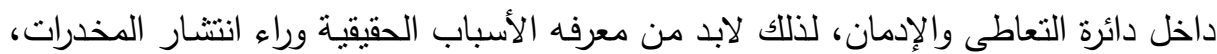
وهناك العديد من المتغيرات الاجتماعية المهيئة للتعاطى مثل: أسلوب الثدة فى المعاملة، أو

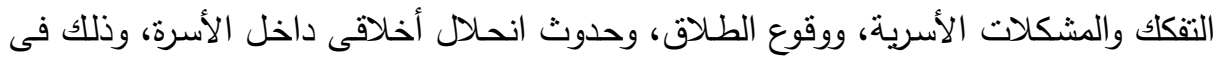

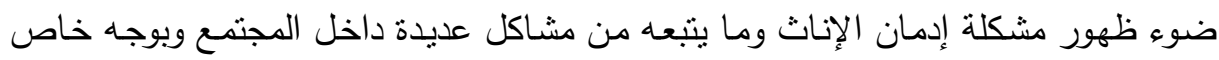

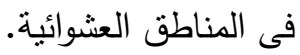
وتعتبر كارثة إدمان الإناث أخطر من إدمان الذكور ولم تعد المشكلة ظاهرة بل تحولت بالفعل إلى كارثة مرعبة بسبب هذا المرض الاجتماعى الخطير الذى يمكن أن ينتشر مثل

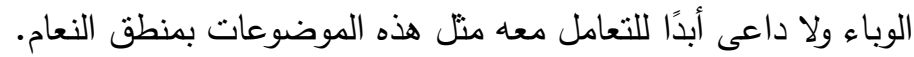

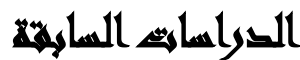

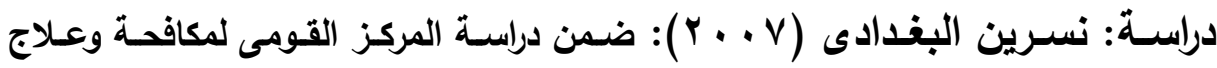
الإدمـان وصندوق مكافحة وعلاج الإدمان والتعاطى، بعنوان: ظـاهرة المخدرات فى الريف

اتخذت هذه الدراسة من الأسلوب الإحصائى منحى أساسيًا فى إطار المنهج المقارن،

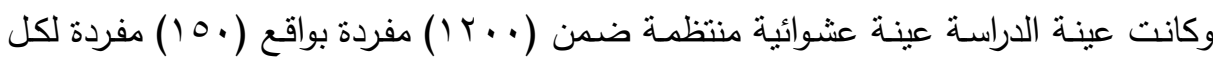

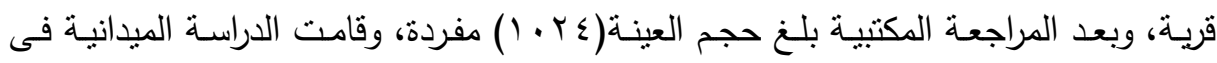
محافظتى الثرقية والمنيا فى ثمان قرى باستخدام أداة الاستبار .

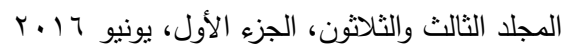


توصلت الدراسة إلى عدة نتائج أهمها: رؤية حوالى (T،؛ \% ) من العينة أن المخدرات

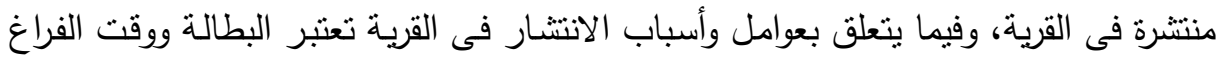

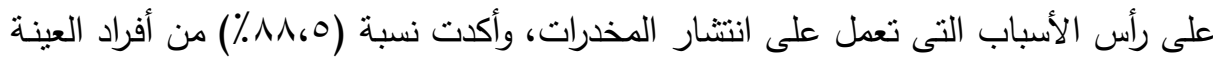
إلى أنهم شاهدون المواد الإعلامية التى تتاولت قضية المخدرات، والتليفزيون من أكثر الوسائل

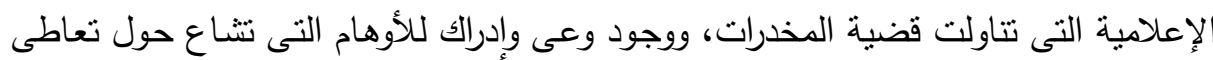
المخدرات، فغالبية العينة لم توافق على المقولات ذات التوجه الذى يدور حول فوائد المخدرات، ولتهات

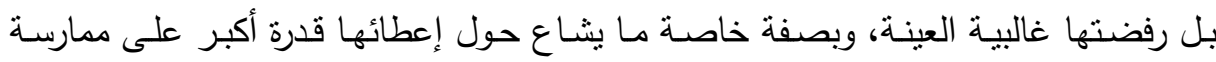

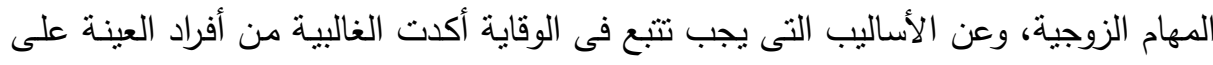

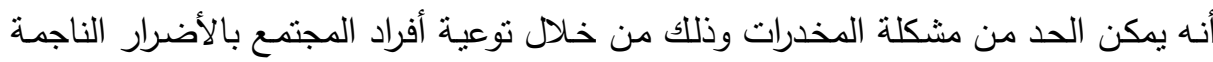
عنها وسد منافذ التهريب، وحل مشكلات الناس وتفريج همومهم، بينما أكدت نسبة (9، ، ــ ٪)

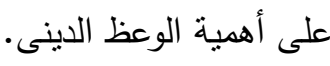

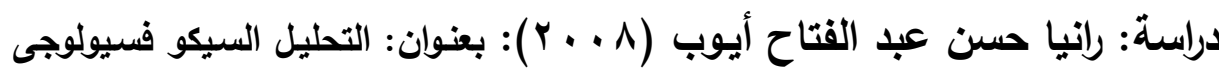
لعينة من الثباب مدمنى البانجو دراسة على مستويات اجتماعية اقتصادية متمايزة تكونت عينة الدراسة مكونة من مجموعتين تضم كل مجموعة ( • (0) مفردة، والمجموعتين

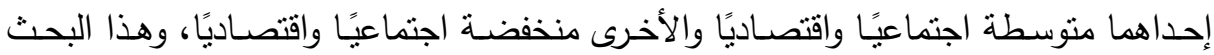
وصفى تحليلى يستخدم المنهج العلمسى من خـلال المسـح الاجتمـاعى بواسطة استخدام أداة

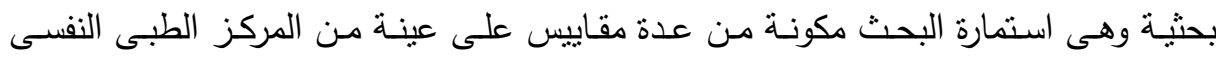
ل الإدمان بجامعة عين شمس.

توصلت النتائج إلى وجود اعتماد إدمانى واضطراب إدمانى سيكوسوماتى وحالة صحية

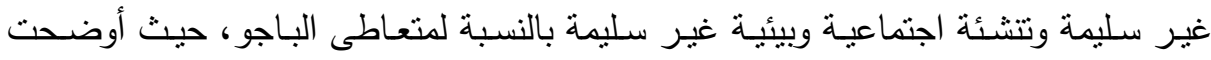

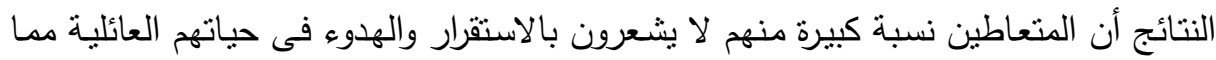

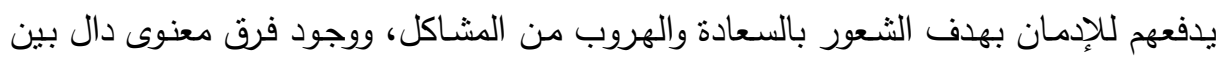

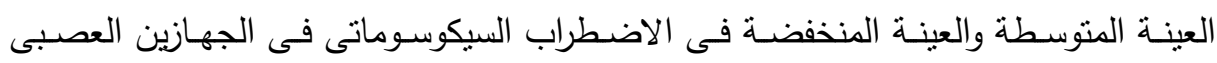

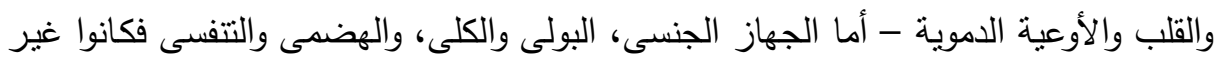


دالين، ووجود فرق معنوى دال بين العينتين المتوسطة والمنخفضة لتقدير الثخصبة للكبار فى

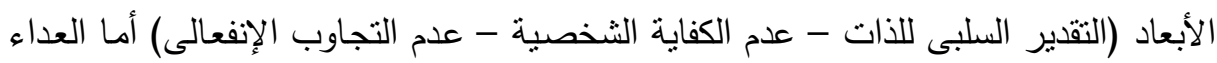
والعدوان والاعتمادية والثبات الإنفعالى والنظرة السلبية للحياة كانوا غير دالين.

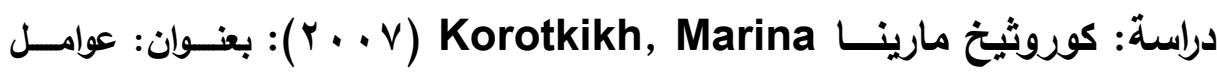
الخطر لتعاطى الماريجوانا بين الروس والكنديين: دراسة تحليل مقارن

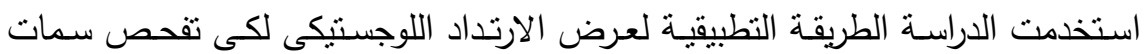
المحبط الاجتماعى الذى ينتج المراهقون المعرضون لأخطار تعاطى المايريجوانا، وتكونت

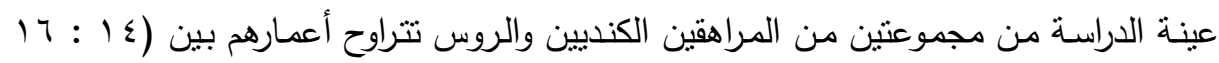
سنة)، وكانت أدوات الدراسة هى تحليل نتائج دراسة منظفة الصحة العالمية والاستخبار . على الرغم من الاختلافات بين البلدان إلا أنه بعرض النتائج تنين أن: الأقران لها لهان التأثير الأقوى على اتعمال المراهق للماريجونا، الناشئة خلال المحيط الاجتماعى للمراهقين الكنديين بعرين

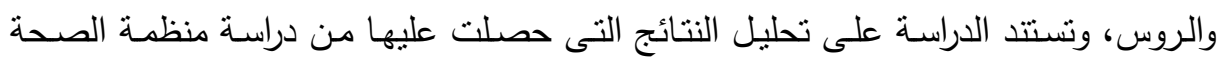

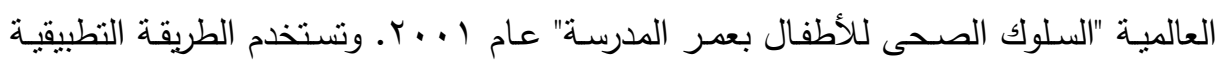
لعرض الارتداد اللوجستيكى لكى تفحص سمات المحيط الاجتمـاعى الذى ينتج المراهقون المعرضون لأخطار تعاطى الماريجوانا، وتكونت عبنة الدراسة من مجموعتين من المراهقون

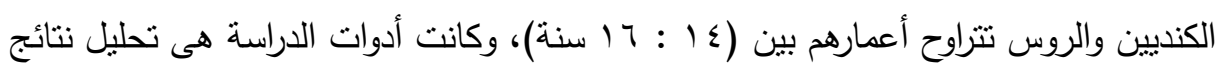

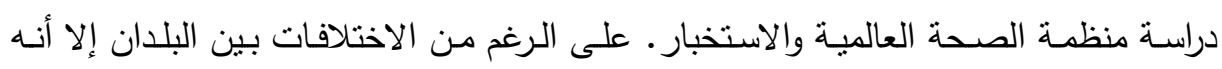

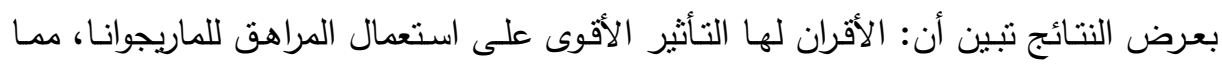

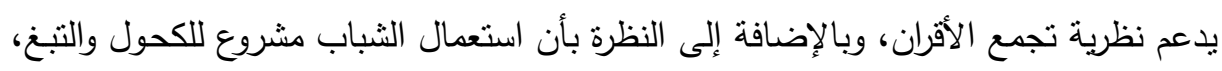

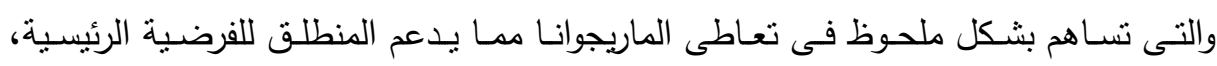

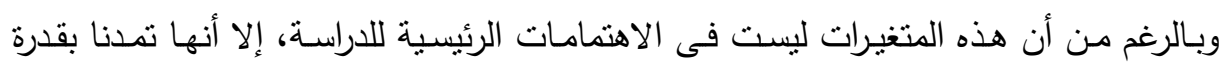

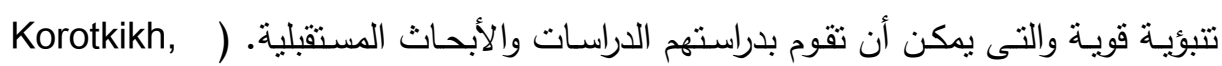

.(Marina: 2007 


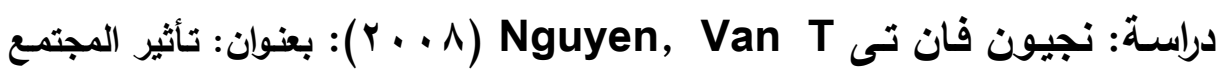
والعائلة والرفاق على الإفراط فى تعاطى المذرات بين الثباب فى فيتنام

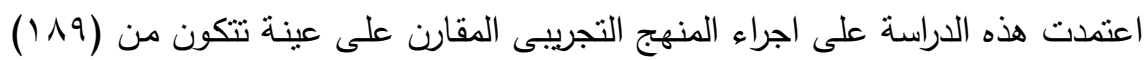

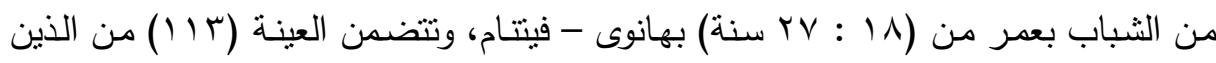
تعاطوا الدخدرات، و (VT) من الذين لم يتعاطوا، وقد استخدمت الدراسة الإحصائية العامة العائة

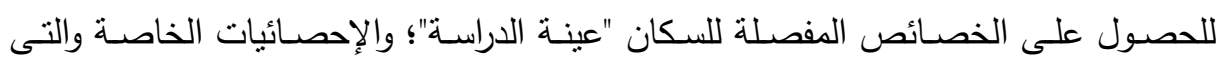

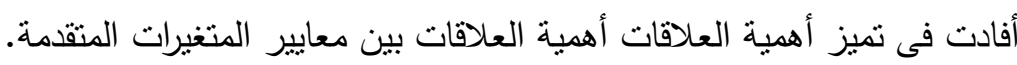

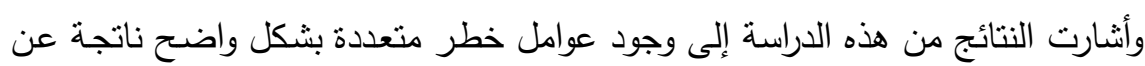

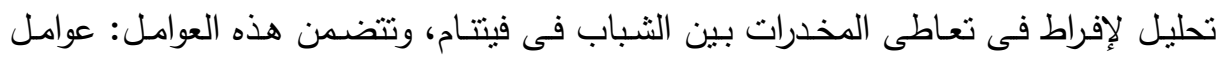

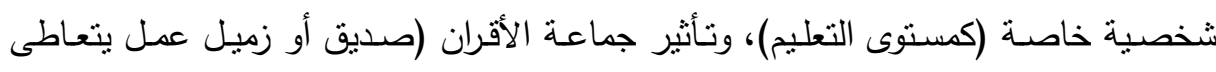
المخدرات)، ودعم المجتمع المحلى (الحى)، وعوامل إجهاد اجتماعى (كالخروج من التعليم).

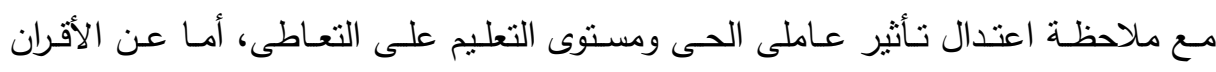

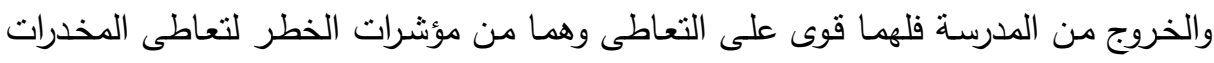

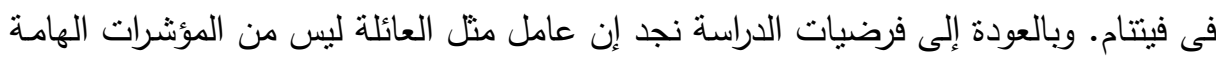

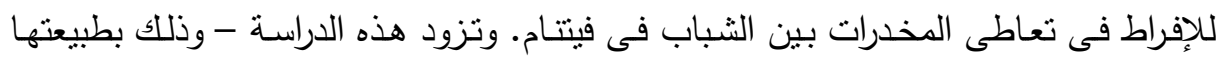

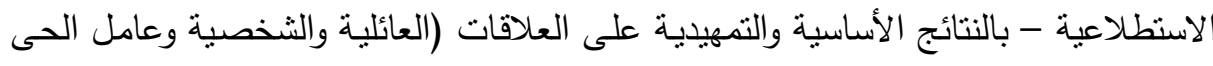

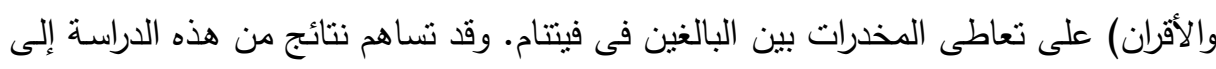

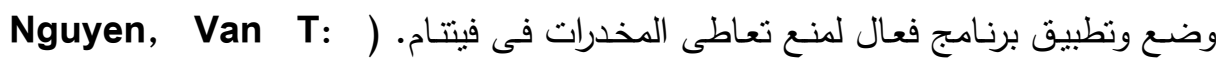

\section{تساولائش الدراسة}

لتحقيق أهداف الدراسة تم طرح عدة تساؤلات على النحو الثالى: 1. ما الظروف الاجتماعية التى بعيش فيها الإناث؟

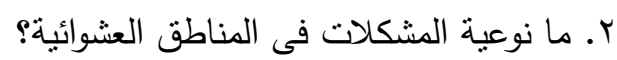


r. ما مدي انتشار ظاهرة الإدمان بين الإناث فى المناطق العشوائية؟

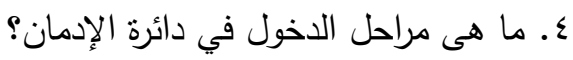

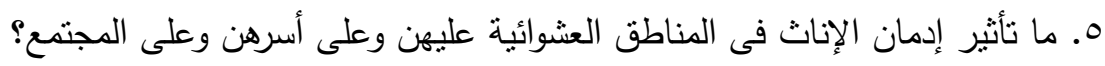

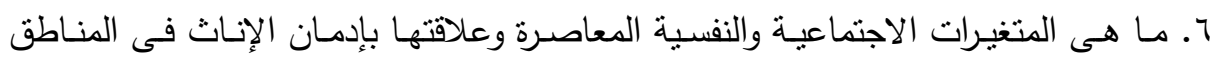
العشوائية؟

\section{أهمية التراسما}

تكمن أهمية الدراسة الحالية فى جانبين: الأول نظرى، والثانى نطبيقى: أولاً: الأهمية النظرية: ا-تسليط الضوء على بعض المتغيرات الاجتماعية والنفسية المعاصرة التى قد تدفع الإناث فى المجتمعات العشوائية إلى الوقوع فريسه للإدمان أو التعاطى.

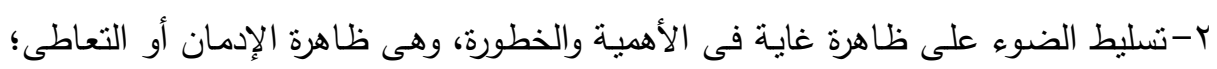
حيث أن حجم هذه الظاهرة زاد وتفاقم على المستوبين المحلى، والدولى فئ. r-نوجيه نظر الباحثين والمتخصصين فى مجال علاج الإدمان أو التعاطى، إلى الأسباب

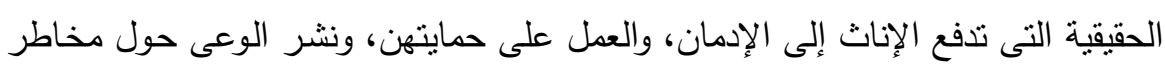
الإدمان، وعواقبه السلبية على الفرد، والمجتمع. ع-توجيه النظر إلى خطورة المشكلات التى تعانى منها المناطق العشوائية، والتى يكون لها لهائه تأثير سلبى على حياة الأفراد وضرورة الحد منها.

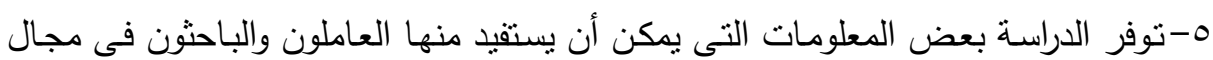
الإدمان والعشوائيات، عند تتاولهم مثل هذه الموضوعات من جوانب أخرى فى المستقبل. 


\section{ثانيًا: الأهمية التطبيقية:}

1-إمكانية الاستفادة من نتائج الدراسة فى عقد دورات استرشادية وبرامج تدريبية لأسر الإناث فى المناطق العشوائية، يكون الهدف منها التعرف على الآثار السلبية للضغوط الوالدية،

$$
\text { والمشكلات الأسرية على سلوك أبنائهم. }
$$

Y-حث المجتمـع على الحرص على الاهنمـام بهذه الفئة حيث ترتفع النسبة فـى أعداد

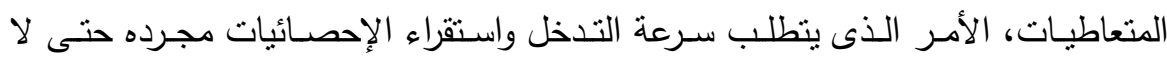

تضللنا الأرقام.

r-اهتمام الدراسـة الحالية بالإناث قد يتيح الاستفادة من طاقاتهم الكامنة واستثمارها بطريقة

$$
\text { نسهل عليهم الانضمام للمجتمع كقوة فعالة. }
$$

ع- إمكانية الاستفادة من نتائج الدراسة فى عقد دورات تدريبية وإرشادية للإناث يكون الهدف

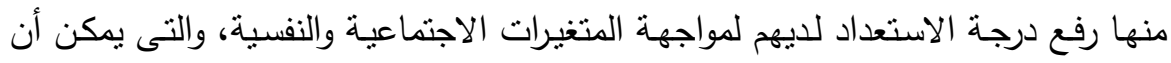

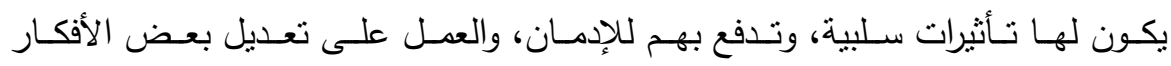

والاتجاهات السلبية لدى الإناث نحو هذه المتغيرات.

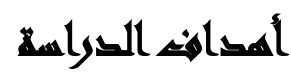

لكل دراسـة هدف تسـعى لتحقبقهـ وتشـعى هذه الدراسـة إلى التعـرف على المتغيـرات الاجتماعية وهي المستوى الاجتماعى، التعليم، المهنة، الحالة الاجتماعية، عدد أفراد الأسرة

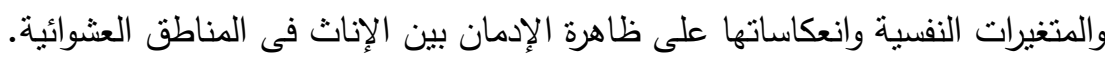
وينبثق من هذا الهدف عدة أهداف فرعية هى: 1- التعرف على مراحل الدخول في دائرة الإدمان. r- التعرف على المتغيرات الاجتماعية المعاصرة وعلاقتها بإدمان الإناث. r-الكثف عن المتغيرات النفسية المعاصرة وعلاقتها بادمان الاناث. ع-رصد ظاهرة إدمان الإناث فى المناطق العشوائية. 0- إلقاء الضوء على الآثار الخطيرة التى يسببها إدمان الاناث. 


\section{مهاهيه السراسمة}

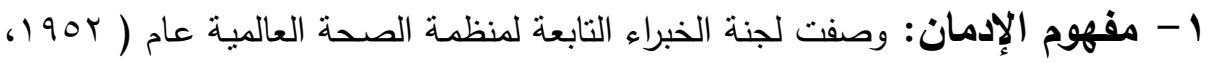

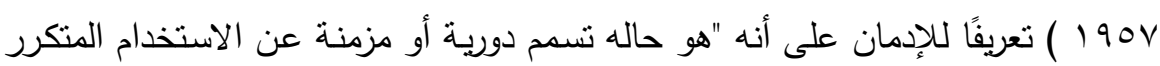
لعقار ما وتتصف بالآتي:

• رغبه غلابة أو حاجة قهرية تدفع الثخص إلى الاستمرار فى تعاطى العقار والحصول عليه بأى وسيلة. • ميل إلى زيادة الجرعة المعطاة من العقار.

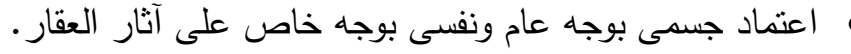

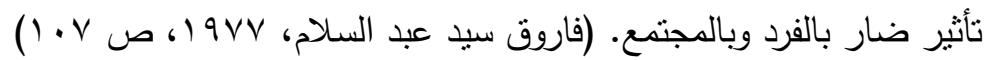
قد أوصت هيئة الصحة العالمية باستبدال كلمه الإدمان والتعاطى بالاعتماد في الستينات

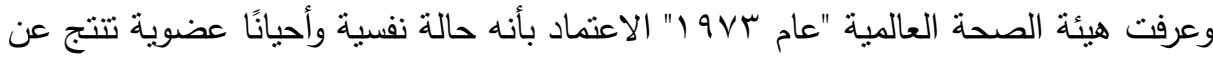

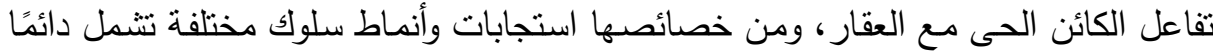

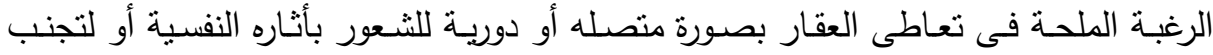
الآثار المزعجه التى تتتج عن عدم توفره، وقد يدمن المتعاطى أكثر من مادة واحدة (عادل

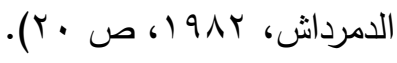

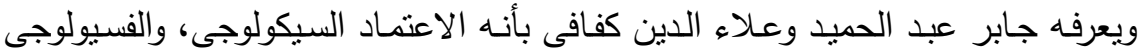

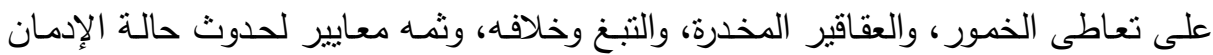

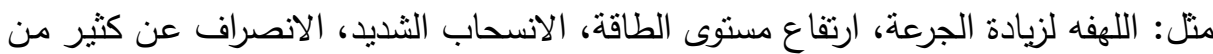

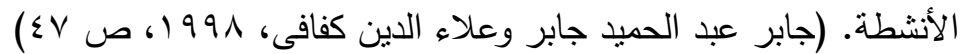
كما يعرف جابر موسى وأخرون الإدمان على أنه حذر أوسكر دورى أو مزمن مدمر اللفرد والمجتمع وينجم عن تكرار استعمال المخدر ومن ظواهره: • • التحمل: أى أن المدمن يتحمل جرعات كبيره من المخدر.

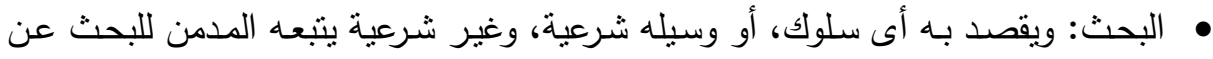

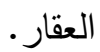




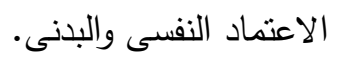

هالانسحاب: ويقصد بـه الأعراض النفسية، أو البدنبة، أو الاثثين معًا، بعد ساعات أو أيام

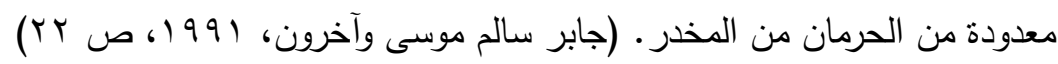

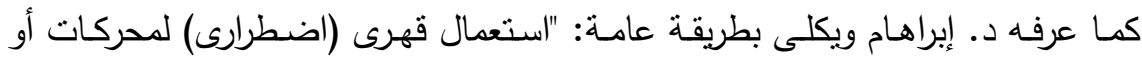

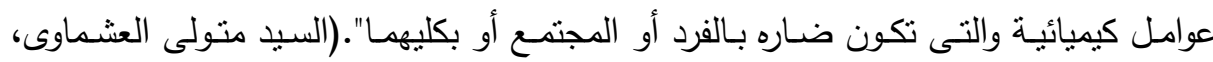

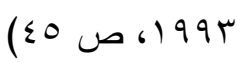

يتبنى الباحث تعريف هيئة الصحة العالمية للإدمان باعتباره حالة نفسية، وأحيانًا عضوية

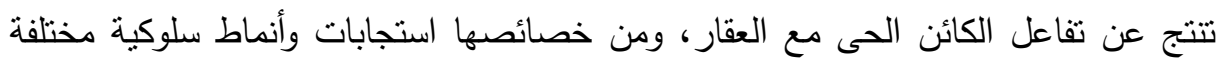
تشمل دائمًا الرغبة الملحة فى تعاطى العقار بصورة منصلة، أو دورية للشعور بآثاره النفسية، أو لتجنب الآثار المزعجة التى تتتج عن عدم توفره.

r- مفهـوم المنـاطق العشـوائية: هنـاك بعض الاختلافات فى إطلاق لفظ العشـوائية

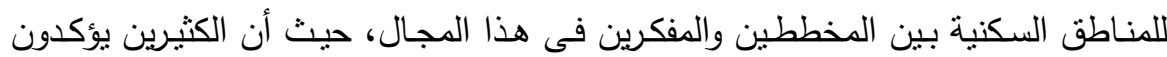
على ضدروة التمييز بين السكن المخالف للقوانين وبين التجمعات السكنية الكبيرة التى

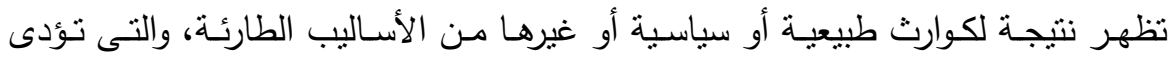

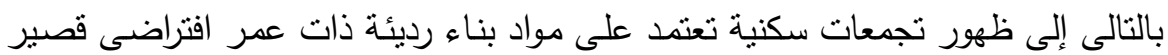

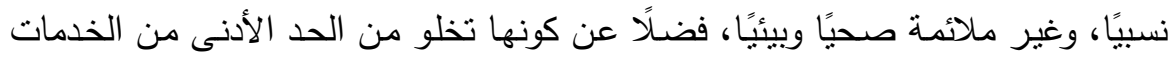

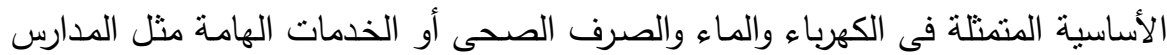

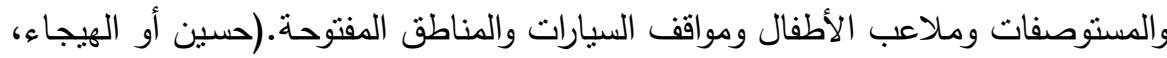

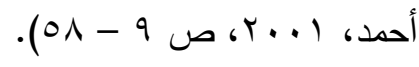

وتعتبر المناطق الخاضعة لقوانين التتظيم مناطق رسمية منظمة، أما خلاف ذلك فيعتبر

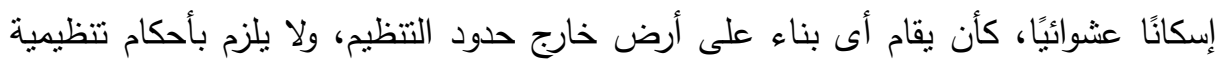
سواء كان حضريًا أو رسميًا. ويحدد قانون التخطيط العمرانى المصرى المنطقة العشوائية بأنها باهي "تلكك المنطقة التى تعانى من التزاحم السكانى وتكون أغلب مبانيها متخلفة ومتهالكة، ويلزم 
إزالتها، أو إعادة تخطيطها، أو تعميرها من جديد، وتفتقر إلى المرافق والخدمات الأساسية.

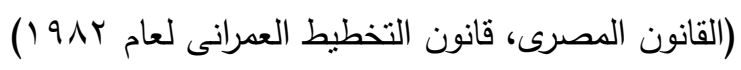

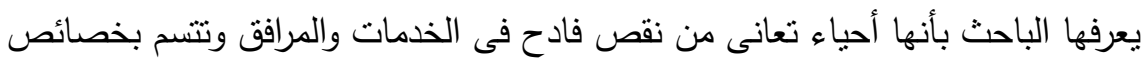

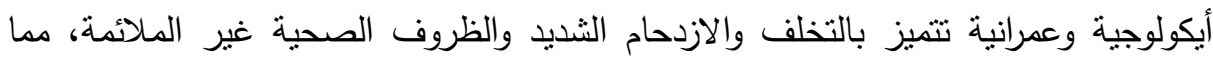
يترتب عليه آثار سلبية على الأمن والأخلاق.

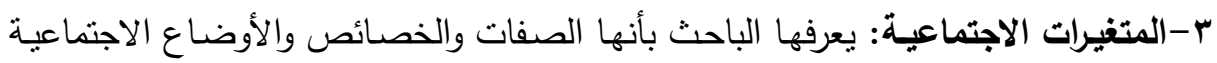

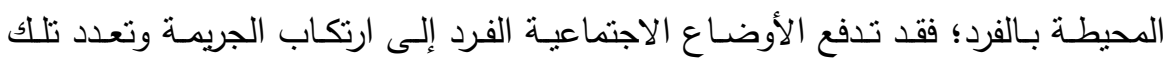

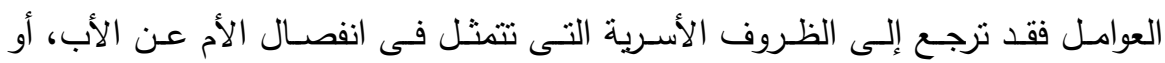
المعاملة القاسية والمشاجرات، أو انتماء الثخص إلى عائلة تجار أو متعاطى مخدرات؛ أو

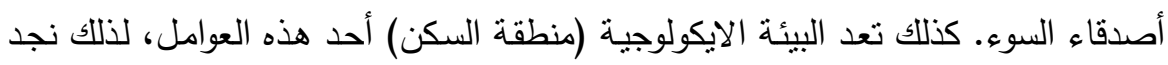
السكن فى العشوائيات من عوامل ارتكاب الجريمة، نظرًا لازدحامها من ناحية، وافتقارها

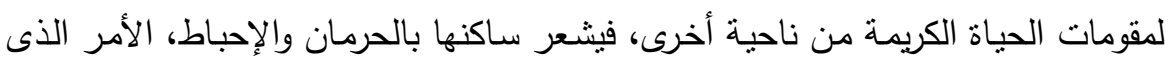
يؤدى إلى اعتبارها أماكن تقريخ الإجرام بل وتصديره أيضًا.

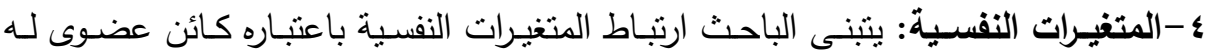
حاجاته ومشكلاته، فإذا عجز عن إثباع حاجاته وحل مشكلاته فإنه بطور الوسائل التى تساعد على الهروب من هذه المشكلات. من هذه الوسائل ابتكار آلية المواد المخدرة كآلية تمنح البشر أجازه من قهر حياتهم اليومية.

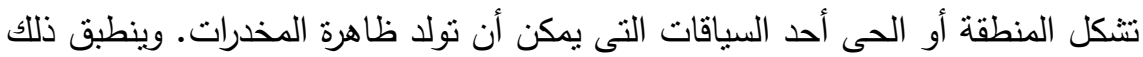
على الأحياء الثعبية والعشوائية، حيث الثعور بالدونية وعدم الأمان وارتفاع معدلات التفكلك بهن الأسرى والبلطجة والسرقة والقتل وكلها سلوكيات ذات صله بتعاطى المخدرات.

كما تتمنل المتغيرات النفسية فى الاكتئاب، وكثره الهموم، وحب الاستطلاع، والرغبة فى زيادة المتعة، والثعور بالحرمان من الحنان. 


\section{هنهمج السواسمة}

تعتبر الدراسـة الحاليـة مـن الدراسـات الوصـفية والتـى تسـتهدف اسـتعراض المتغيـرات

الاجتماعية والنفسية المعاصـرة وعلاقتها بانتشـار ظـاهرة إدمان بين الإنـاث فى المجتمعات

العثوائية.

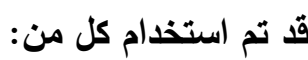

1-منهج المسح الاجتماعى بالعينة كمنحى أساسى للاراسة. r- المنهج الإحصائي لتحليل البيانات

\section{x.بsing}

تتكون عينة الدراسة من (اء) مفردة من الإناث تم اختيارهن مع مراعاة أن يمنلن مجتمعاتهن (المناطق العشوائية)، وكانت العينة عمدية من الإناث اللاتي تتعاطى المخدرات في المناطق العشوائية. 1-المجال الزمنى للاراسة: استغرقت مدة الدراسة حوالى سنة نظرًا لصعوبة الحصول على العينة التى تتوافر فيها الثروط الأساسية للبحث. r-المجال المكانى للاراسة: تم تطبيق الاستمارة فى مستشفى الأمراض النفسية بالعباسية. r-أدوات الدراسةة: تتمثل أدوات الدراسة الحالية فى محورين أساسين هما: 1 - استمارة الاستبيان (من إعداد الباحث): قد روعى فى إعداد استمارة الاسنتيان اختبار معيار للصدق وهو صدق المحكين حيث تم عرض الاستمارة على المختصبن وأفادوا بأنها تصلح لقياس متغيرات الدراسة. كانت استمارة الاستبيان مكونة من •^ عبارة تتشل البيانات الديموجرافية والابعاد الثالية:

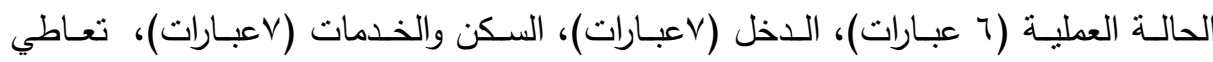
المخدرات (17 عبارة)، تأثير التعاطي ومحاولة الإقلاع عنه (• (1 عبارات) ، العلاقة بالاخرين 
(ع عبـارات)، المشـاركة السياسـية (جعبـارات)، المتعـاطون والمسـتقبل (0عبـارات)، أفكـار وتصورات حول التعاطي (r عبارات)، وتم حساب ثبات استمارة الاستبيان وكانت جميعها قيم وني

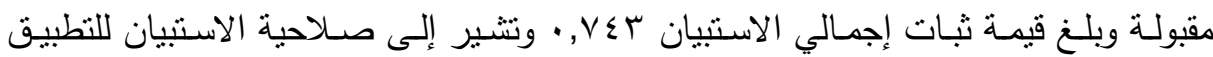

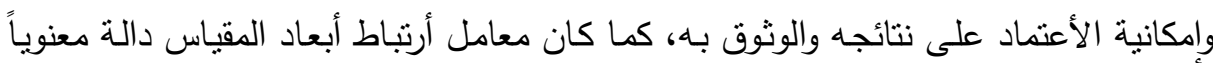
عند مستوى معنوية (1 . , ·) مما يؤكد على صدق الأتساق الداخلي لأبعاد المقياس.

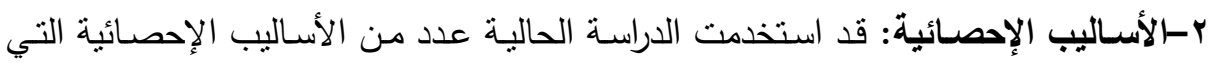
تتمثل في الجداول والنسب المئوية والمنوسطات. التساؤل الأول: ما هى الظروف الاجتماعية التى يعيش فيها هؤلاء الإناث؟

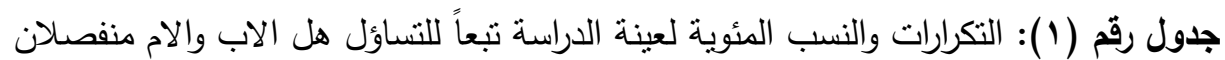

\begin{tabular}{|c|c|c|c|c|}
\hline الدلالة المعنويـة & L & $\%$ & العدد & المتغيرات \\
\hline \multirow{3}{*}{$\cdot, \ldots l$} & \multirow{3}{*}{$10, Y \backslash 1$} & $r 7,1$ & 11 & V \\
\hline & & $V \Psi, Y$ & $r$. & نعح \\
\hline & & $1 \ldots$ & 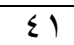 & \\
\hline
\end{tabular}

التصدع الأسرى: اتضح من خلال تتبع الحالات أن التصدع المادى للأسرة من أهم عوامل

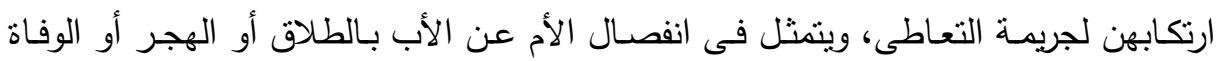

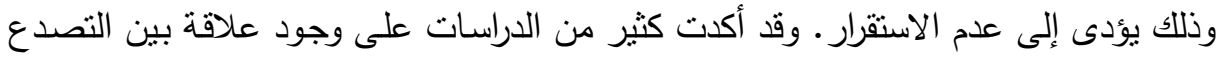

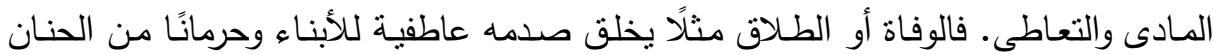

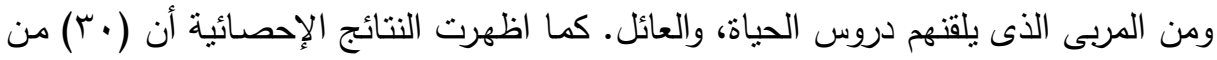

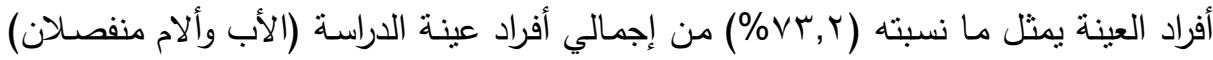

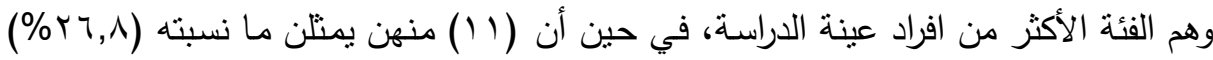

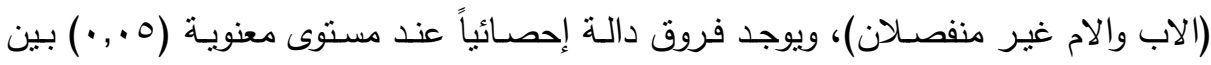

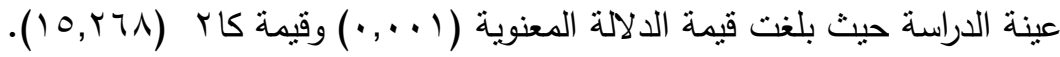


جدول رقـم(ץ): التكرارات والنسب المئويـة لعينـة الدراسـة تبعاً للنسـاؤل اول شخص قدم لها المخدرات

\begin{tabular}{|c|c|c|c|c|}
\hline الدلالة المعنويةً & 5 & $\%$ & العدد & المتغيرات \\
\hline \multirow{5}{*}{$\cdot, \cdots)$} & \multirow{5}{*}{$\mid V, \leqslant \Psi q$} & $01, Y$ & YI & صديقة \\
\hline & & $V, r$ & $r$ & قريبة \\
\hline & & 47,7 & 10 & الزوج \\
\hline & & $\varepsilon, 9$ & Y & جارة \\
\hline & & $Y, \varepsilon$ & 1 & شاب \\
\hline
\end{tabular}

انتماء المبحوثة لأسرة تتعاطى المخدرات: قررت بعض المبحوثات أن أسرهن كانت السبب فى تعاطهن، فالزوجة فى أحيان كثيرة تدخل إلى عالم المخدرات عن طريق أسرتها، سواء

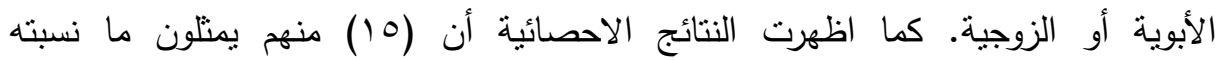

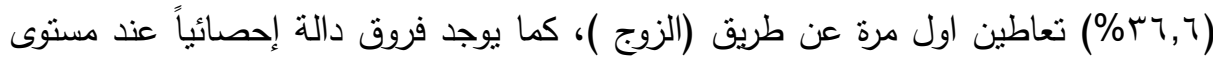

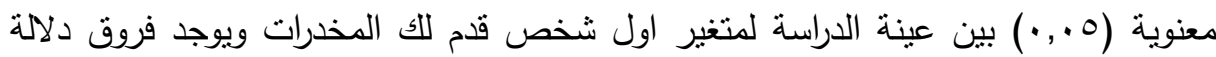

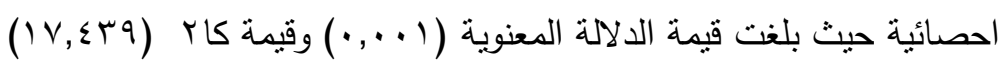
أصدقاء السوء: يوجد ارتباط وثثق بين صداقة السوء والانحراف، فاختيار الصديق بمكن أن

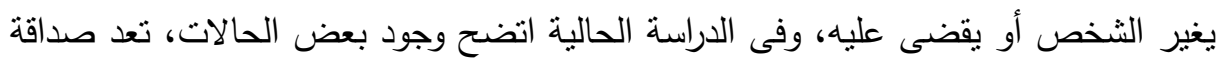

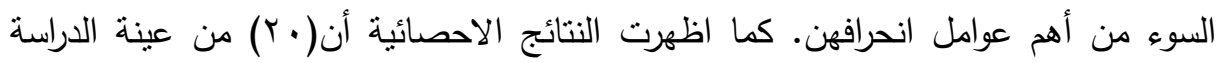

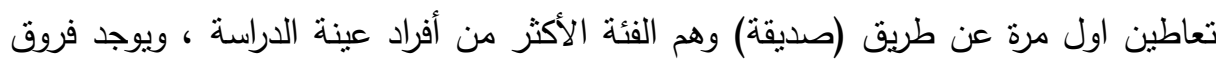

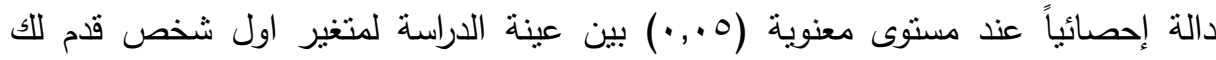

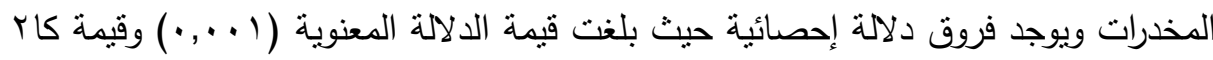


جدول رقم(ץ): التكرارات والنسب المئوية لعينة الدراسة تبعاً لمشكلة السكن

\begin{tabular}{|c|c|c|c|c|c|}
\hline \multicolumn{3}{|c|}{ 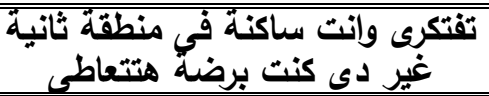 } & \multicolumn{3}{|c|}{ يا ترى انت راضية عن المنطقة اللى انت ساكنة فيها } \\
\hline$\%$ & العدد & المتغيرات & $\%$ & 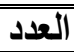 & المتغيرات \\
\hline TY & 9 & نعم & $M, Y$ & 0 & راضية \\
\hline 71 & ro & $y$ & 9,1 & $\varepsilon$ & راضية الى حد ما \\
\hline \multirow{2}{*}{$1 V, 1$} & \multirow{2}{*}{$\mathrm{V}$} & \multirow[t]{2}{*}{ ل لاعرف } & VA & rt & غير راضية \\
\hline & & & $1 \ldots$ & «1 & الإجمالى \\
\hline \multicolumn{2}{|c|}{$1 \leq, Y \leq \varepsilon$} & كا' & \multicolumn{2}{|c|}{$r q, 9 r$} & S \\
\hline \multicolumn{2}{|c|}{$\cdot, \cdots 1$} & الالالة المغنوية & \multicolumn{2}{|c|}{$\cdot, \cdots 1$} & الالالئة المعنويةً \\
\hline
\end{tabular}

مشكلة السكن: أكدت بعض المبحوثات أن مشكلة السكن من أهم العوامل التى تؤدى إلى التعاطى حيث يهرب المتعاطى من واقعة المؤلم إلى عالم المخدرات كى ينسى همومه، وقد يقوده ذلك إلى ارتكاب بعض الجرائم نتيجة الثعور بالحرمان والإحباط ومحاولة الهروب من

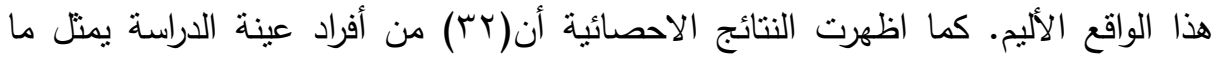
نسبته (\%^) من إجمالي أفراد عينة الدراسة (غير راضيات عن منطقة السكن) وهم الفئة الأكثر من أفراد عينة الدراسة ، ويوجد فروق دالة إحصائياً عند مستوى معنوية عند مستوى راتئه معنوية (0.., •) بين عينة الدراسة لمتغير الرضا عن السكن حيث بلغت قيمة الدلالة المعنوية

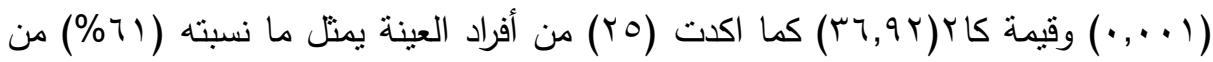
إجمالي أفراد عينة الدراسة (عدم التعاطى فى حالة وجودهن فى منطقة اخرى) وهم الفئة الأكثر من أفراد عينة الدراسة، ويوجد فروق دالة إحصائياً عند مستوى معنوية (ه.,. •) بين

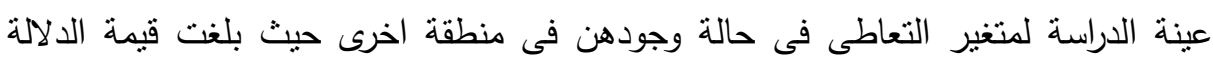

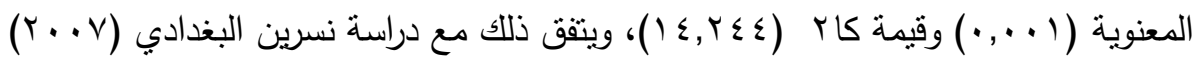


التساؤل الثانى: ما هى نوعية المعاناة فى المناطق العشوائية؟

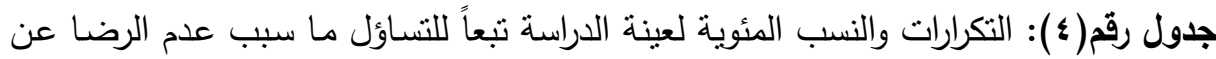

\begin{tabular}{|c|c|c|c|c|}
\hline الالالةٌ المعنويةً & ك & $\%$ & العدد & المتغيرات \\
\hline$\cdot, \boldsymbol{\varepsilon}$ & $\cdot, 71$. & $\varepsilon r, 9$ & 11 & ازدحام وضوضاء المنطقة \\
\hline$\cdot, \cdot \varepsilon$ & $\varepsilon, I Y Y$ & 70,9 & TV & المكان عير صحي \\
\hline-- & -- & $\cdot$ & $\cdot$ & السكان مهددين بالانتقال منه \\
\hline$\cdot, \cdots \Lambda$ & $V, \cdot \varepsilon$ & $r q, r$ & Ir & كثرة المشاحنات بين الآهالي \\
\hline$\cdot, 7$ & $\cdot, Y Y \cdot$ & or, $\mathrm{V}$ & tr & انتشار تجارة المخدرات \\
\hline$\cdot, \cdots \wedge$ & $V, \cdot \varepsilon$ & $V \cdot, V$ & rq & انتشار تعاطي المخدرات \\
\hline$\cdot, \cdot r$ & $\Lambda, \wedge \cdot 0$ & $r\urcorner, \Lambda$ & 11 & الخوف من سلوك المتعاطين \\
\hline$\cdot, \cdots 1$ & $r v, .9 \Lambda$ & $Y, \varepsilon$ & 1 & عدم وجود مستشفي حكومى \\
\hline$\cdot, \cdot \varepsilon$ & $\varepsilon, I Y Y$ & $\Gamma \varepsilon, 1$ & $1 \varepsilon$ & اننشار القمامة في الثوارع \\
\hline$\cdot, \cdots 1$ & $\mathrm{rv}, 91$ & $r, \Sigma$ & 1 & حرق القمامة \\
\hline$\cdot, \cdots 1$ & $1 Y, 9 \cdot r$ & rt & 9 & عدم وجود دوريات للأمن \\
\hline$\cdot, \varepsilon$ & $\cdot, 71 \cdot$ & $\cdot$ & $\cdot$ & البعد عن مكان العمل \\
\hline$\cdot, \cdot r$ & $\Lambda, \Lambda \cdot 0$ & $\varepsilon r, q$ & 11 & كثرة الانحرافات الاخلاقية \\
\hline$\cdot, \cdots 1$ & $\Lambda, \wedge \cdot 0$ & $r \eta, \Lambda$ & 11 & عدم وجود تهوية \\
\hline
\end{tabular}

يعانى السكان فى المناطق العشوائية من تدنى شروط السكن والحياة. فالثوارع تكاد تكون منعدمة، وتلاصق المساكن والتكس داخلها ظاهرة واضحة، مما يؤدى إلى استباحة الخصوصية. ويؤدى الازدحام فى المسكن إلى مشاكل ومشاجرات بين أفراد الأسرة، كما يؤدى دونى

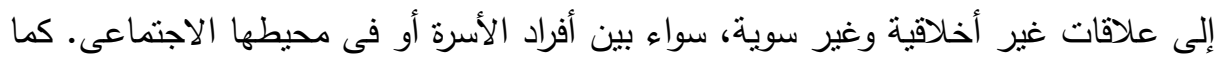
يشعر السكان بعدم الرضا عن السكن بسبب انتشار المخدرات وكثره الانحرافات الأخلاقية

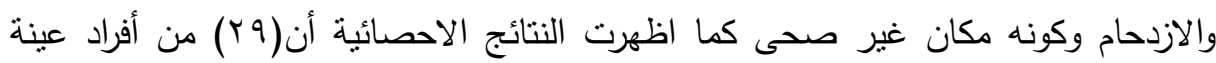

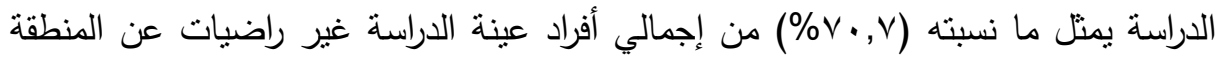

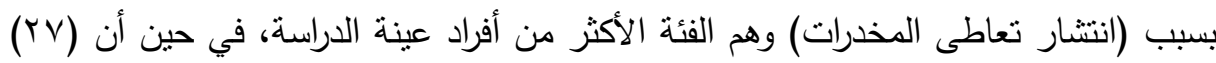

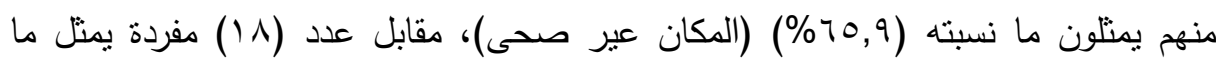

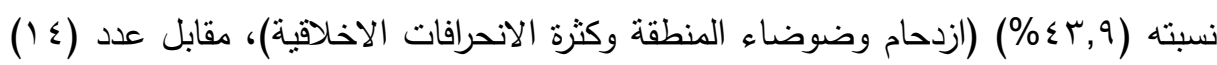

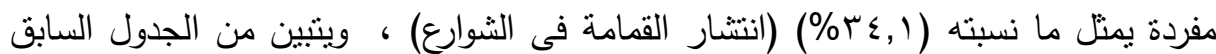

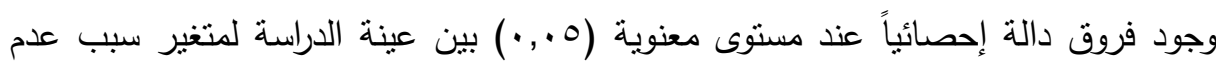




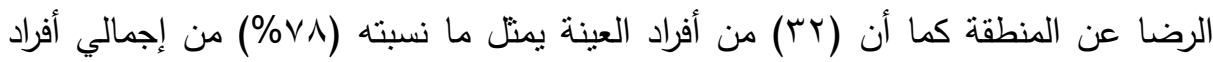

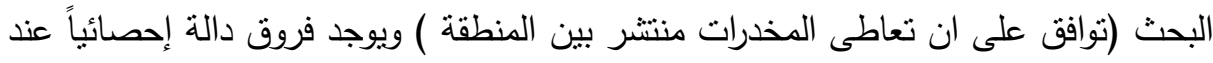
مستوى معنوية عند مستوى معنوية (0. . •) بين عينة الدراسة لمتغير انتتار تعاطى المخدرات

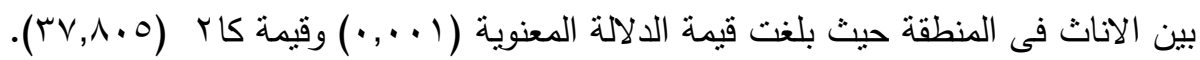

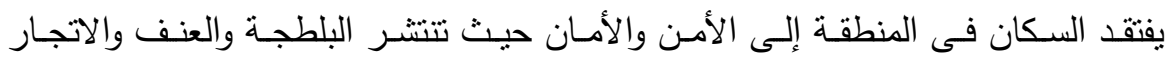

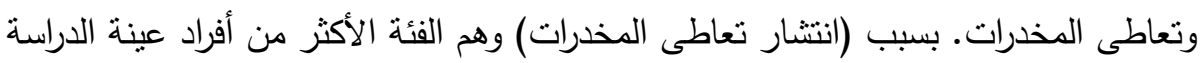
(YV)

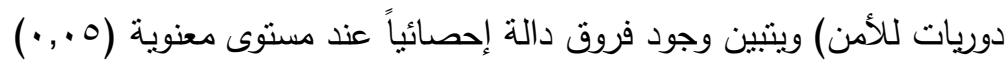

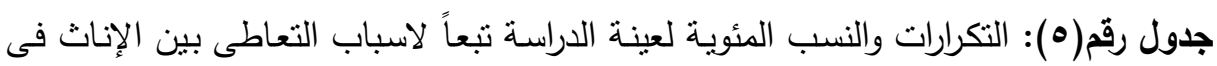
المنطقة

\begin{tabular}{|c|c|c|c|c|}
\hline المعنوية & sis & $\%$ & 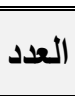 & المتغيرات \\
\hline$\cdot, \cdot \varepsilon$ & $\varepsilon, I Y Y$ & $r \varepsilon, 1$ & $1 \varepsilon$ & الفقر \\
\hline$\cdot, \cdots 1$ & $r V, .91$ & $T, \xi$ & 1 & 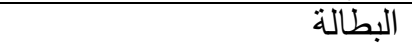 \\
\hline$\cdot, \cdots 1$ & $r \mu, r q$. & $\varepsilon, 9$ & $r$ & ضيق السكن \\
\hline-- & -- & . & . & كثرة المال \\
\hline$\cdot, \cdots 1$ & $r r, r q$. & $\varepsilon, 9$ & $r$ & عدم وجود نوادى او ساحات \\
\hline$\cdot, \cdots \wedge$ & $v, \cdot \leq q$ & $\overline{r q, \Gamma}$ & ir & عدم وجود امن \\
\hline$\cdot, \cdots 1$ & $r r, v r q$ & IY,Y & 0 & انتشار البلطجة \\
\hline$\cdot, \cdot 9$ & $r, 901$ & T५, & 10 & سهولة الحصول على المخدر \\
\hline$\cdot, \cdots 1$ & $T \cdot, 01 Y$ & $1 \leqslant, 7$ & 7 & قضاء معظم الوقت في الثارع \\
\hline
\end{tabular}

يشعر السكان بأنهم شرائح مغتربة اجتماعيًا منصارعة من أجل البقاء، مستخدمه للعنف والانحراف من أجل تحقيق ذللك. اظهرت النتائج الاحصائية أن(10) من أفراد عينة الدراسة

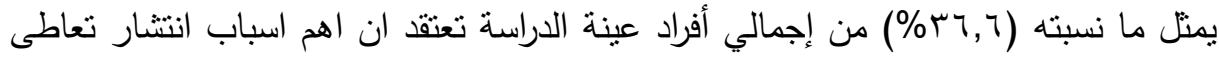

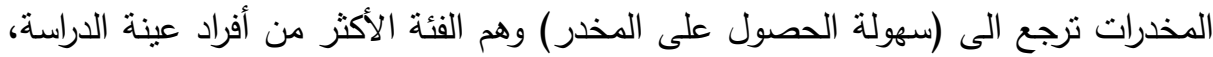

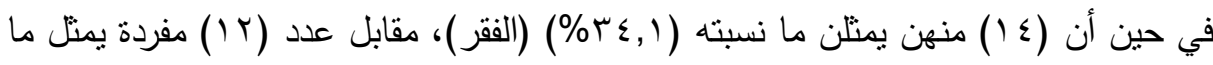

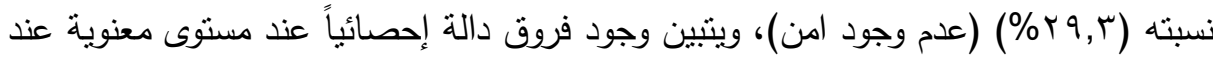


مستوى معنوية (0., •) بين عينة الدراسة لمتغير سبب انتشار تعاطى المخدرات بين الاناث

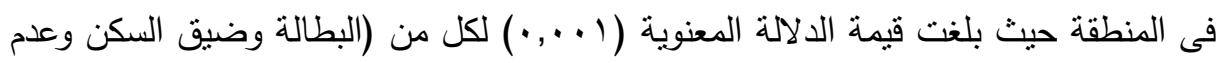

وجود نوادى او ساحات وقضاء معظم الوقت فى الثارع وانتشار البلطجة)

جدول رقم(†): التكرارات والنسب المئوية لعينة الدراسة تبعاً لمستوى التعليم (الوالد - الوالدة)

\begin{tabular}{|c|c|c|c|c|}
\hline \multicolumn{2}{|c|}{ الحالة التعليمية للوالدة } & \multicolumn{2}{|c|}{ الحالة التعليمية للوالد } & \multirow{2}{*}{ المتغيرات } \\
\hline$\%$ & العدد & $\%$ & العدد & \\
\hline$V \Psi, Y$ & $r$. & Or,V & TY & امى - (مي \\
\hline 9,1 & $\varepsilon$ & $1 \varepsilon, 7$ & 7 & يقرا و يكتب \\
\hline \multirow[t]{2}{*}{$r, \varepsilon$} & 1 & 9,1 & $\varepsilon$ & تعليم ابتدائى \\
\hline & & $\varepsilon, 9$ & r & تعليم اعدادى \\
\hline $\mathrm{V}, \mathrm{r}$ & $\mu$ & 9,1 & $\varepsilon$ & ثانوى فنى \\
\hline \multirow[t]{2}{*}{$\varepsilon, q$} & r & $r, \varepsilon$ & 1 & فوق المتوسط \\
\hline & & $r, \xi$ & 1 & جامعى \\
\hline$T, \xi$ & 1 & $r, \xi$ & 1 & فوق الجامعى \\
\hline $1 \ldots$ & « & $1 \ldots$ & « & الإجمالى \\
\hline $90, Y \leqslant \leqslant$ & كا & & & is \\
\hline$\cdot, \cdots 1$ & الالالة المعنويةة & & & الدالة المعنوية \\
\hline
\end{tabular}

يلاحظ انخفاض قيمة النعليم والحرص عليه لدى السكان، وهو ما يعود لأسباب عدة،

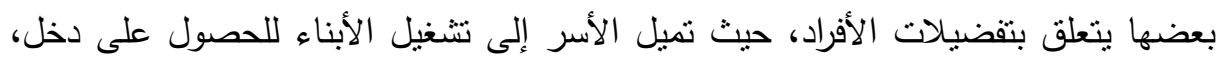

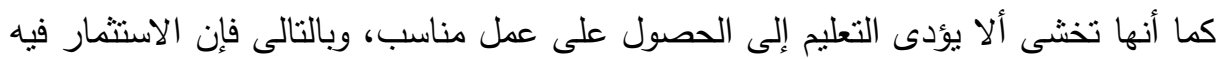

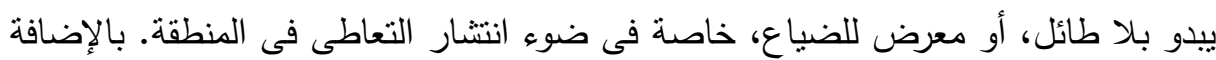

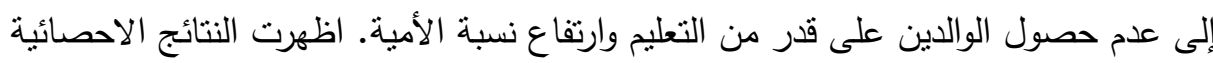

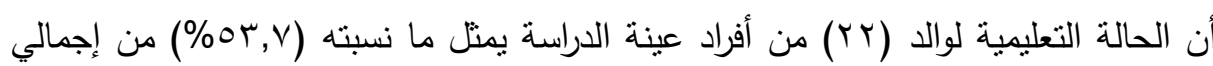

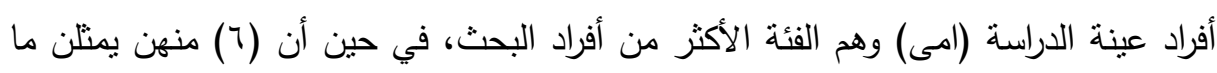

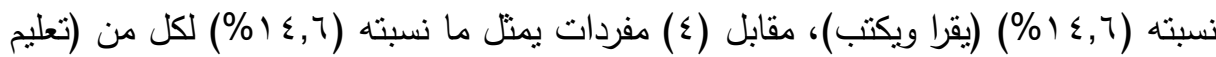
ابتدائى وثانوى فنى )، متكرر وفشل دراسي) ،و عدد (Y) مفردة يمثل ما نسبته (9, §\%)

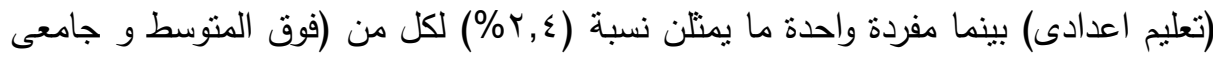
وفوق الجامعي)، ويتبين من وجود فروق دالة إحصائياً عند مستوى معنوية (0. . •) بين عينة 
الدراسة لمتغير الحالة التعليمية للوالد حيث بلغت قيمة الدلالة المعنوية (1 ..,.•) وقيمة كاץ

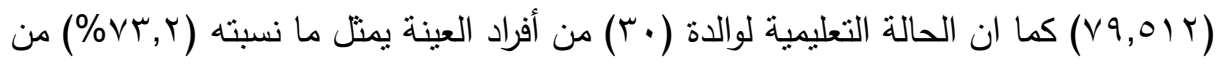

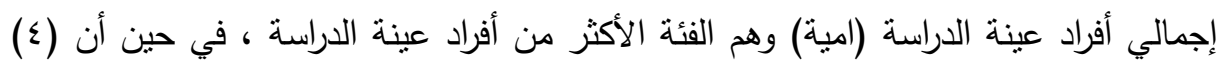

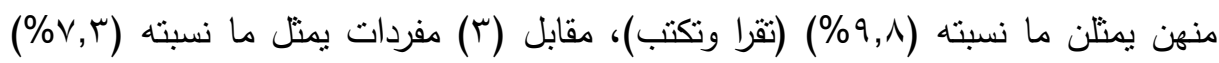

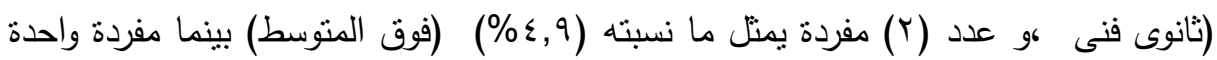

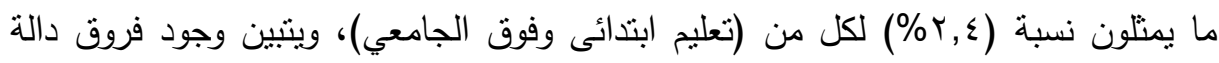

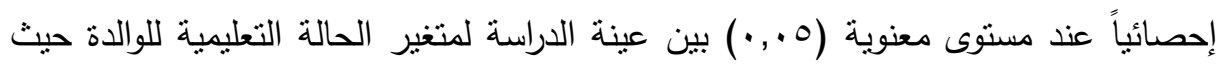

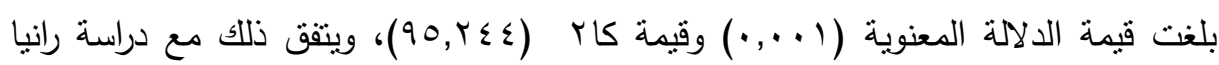

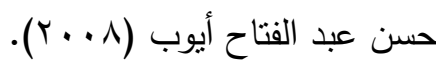

التساؤل الثالث: كيف انتشرت ظاهرة الإدمان بين الإناث فى المناطق العشوائية؟

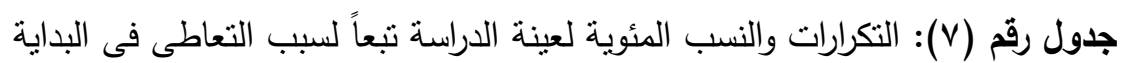

\begin{tabular}{|c|c|c|c|c|}
\hline المعنوية & كا'r & $\%$ & العدد & المتغيرات \\
\hline$\cdot, \cdots 1$ & $r V, .9 \Lambda$ & $r, \varepsilon$ & 1 & الثشعور بالفراغ \\
\hline$\cdot, \cdots 1$ & $\mu r, \mu q$. & $\varepsilon, 9$ & r & التسلية \\
\hline$\cdot, \cdots 1$ & $\mu r, r q$. & $\varepsilon, 9$ & r & تقليد الاصدقاء \\
\hline$\cdot, \cdots 1$ & $r q, \wedge \vee \wedge$ & $V, r$ & $\mu$ & على سبيل التجربة \\
\hline$\cdot, \cdots \wedge$ & $V, \cdot \varepsilon$ & $r q, r$ & IT & عزومة من صديق \\
\hline$\cdot, \cdots 1$ & 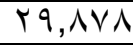 & $V, r$ & $\mu$ & مشاكل اسرية \\
\hline-- & -- & - & - & مشاكل في العمل \\
\hline$\cdot, \cdots 1$ & 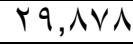 & $\mathrm{V}, \mathrm{r}$ & $r$ & تفكلك اسرى \\
\hline-- & -- & . & - & كثرة المال \\
\hline$\cdot, \cdots 1$ & $r \mu, \varepsilon r q$ & $M, Y$ & 0 & الرغبة في نسيان الهموم \\
\hline
\end{tabular}

أكدت نتائج الدراسة أن بعض الحالات بدأت فى سن مبكر (11 سنة) وجاءت الرغبة

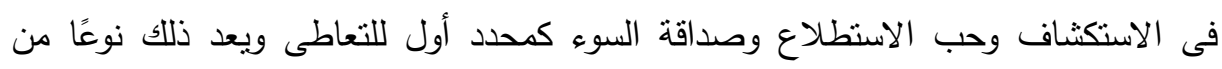
التحريض غير المباشر. لكن الأخطر منه التحريض المباشر على التعاطى من جانب أحد أفراد الأسرة منل الزوج كما تشجع بعض الأفكار والتصورات الثائعة على تعاطى المخدرات

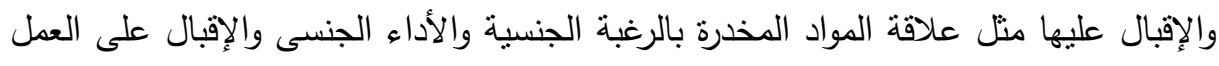

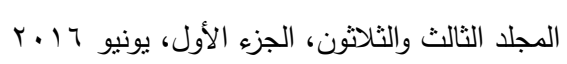


وتحمل العمل الثاق أو نسيان الهموم والإحساس بالضيق ويعد وجود المخدرات بكثرة وسهولة

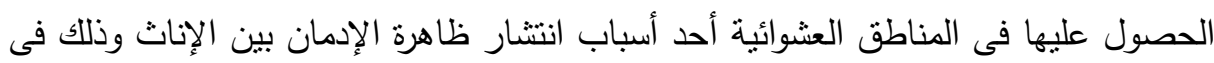
ظل الغياب الأمنى والضبط الاجتماعى حيث أكدت معظم الحالات عدم تعاطيهن المخدرات

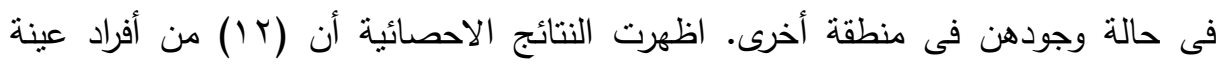

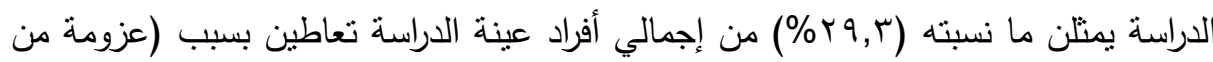

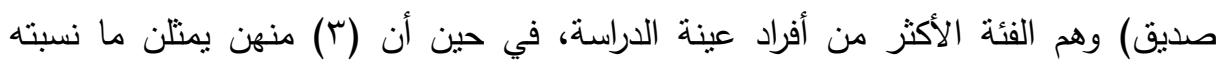

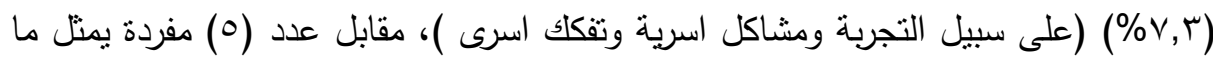

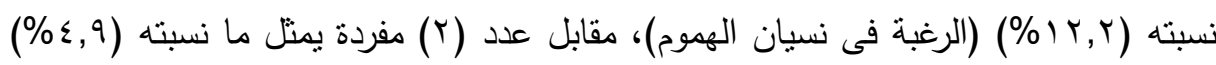

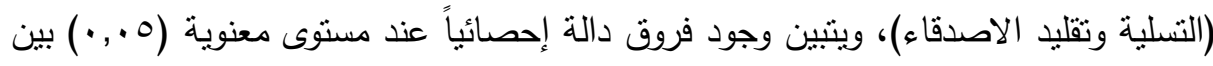
عينة الدراسة لمتغير سبب التعاطى ويوجد فروق دلالة احصائية حيث بلغت قيمة الدلالة

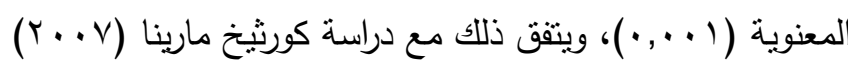
التساؤل الرابع: ما هى مراحل السقوط فى هوة الإدمان؟

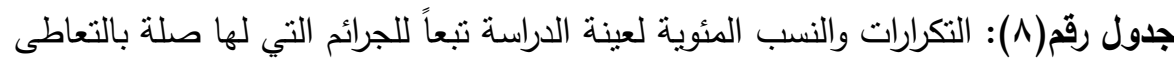

\begin{tabular}{|c|c|c|c|c|}
\hline الالالة المعنوية & 'L & $\%$ & العدد & المتغيرات \\
\hline (,,$\ldots 1$ & Y7,071 & $9,1,1$ & $\overline{\varepsilon \xi}$ & الاغنصاب \\
\hline$\cdot, \cdots 1$ & $M, q \cdot Y$ & $V \wedge$ & Tr & السرقة \\
\hline$\cdot, \cdots 1$ & $1 Y, q \cdot r$ & YY & 9 & الضرب \\
\hline$\cdot, \Gamma$ & 1,190 & $0 \wedge, 0$ & $T \varepsilon$ & البلطجة \\
\hline$\cdot, \cdot \varepsilon$ & $\varepsilon, 1 Y Y$ & 70,9 & TV & الدعارة \\
\hline
\end{tabular}

اتضـح مـن خـلال تتبع الحـالات أن بدايـة السقوط فـى هـوة الإدمـان تكون عن طريق

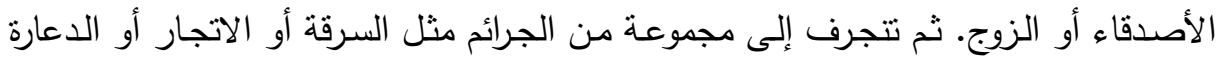

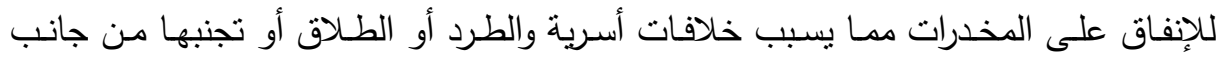

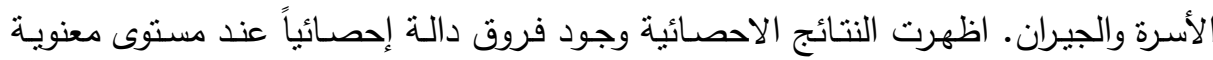

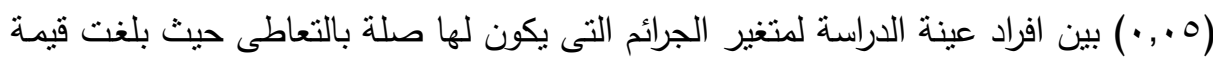
الدلالة المعنوية ( ( . ., ) ) لكل من (الاغتصاب والسرقة والضرب) 
جدول رقم(9): التكرارات والنسب المئوية لعينة الدراسة تبعاً لإجابة التساؤل التوقف عن

\begin{tabular}{|c|c|c|c|c|c|}
\hline \multicolumn{6}{|c|}{ التعاطي } \\
\hline \multicolumn{3}{|c|}{ ايه اسباب فثلكل } & \multicolumn{2}{|c|}{ هل نجحتى فُ التوقف أم فشُتحى } & \multirow{2}{*}{ المتغيرات } \\
\hline$\%$ & العدد & المتغيرات & $\%$ & ألعداد & \\
\hline$\overline{V T, V}$ & $1 \leq$ & مقدرتش ابطل & $V q, Y$ & 19 & فتثلت \\
\hline $1 \ldots$ & 19 & فثلت & $r \cdot, \Lambda$ & 0 & نجحت \\
\hline 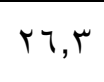 & 0 & سلي الرخدر الحصول & $1 \cdots$ & $r \varepsilon$ & تتعاطيى مخدرات تبطلى \\
\hline \multicolumn{2}{|c|}{$\Lambda, \wedge r q$} & كا & \multicolumn{2}{|c|}{$1 \mu, \cdot V \mu$} & 'ا \\
\hline \multicolumn{2}{|c|}{$\cdot, ., 1$} & الدلالة المعنوية & \multicolumn{2}{|c|}{$\cdot, \ldots 1$} & الدلالة المعنوية \\
\hline
\end{tabular}

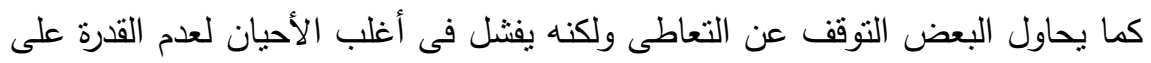

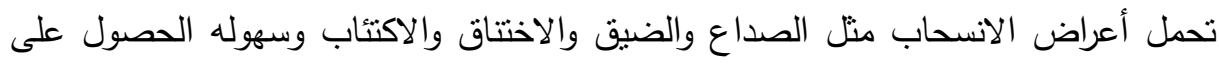

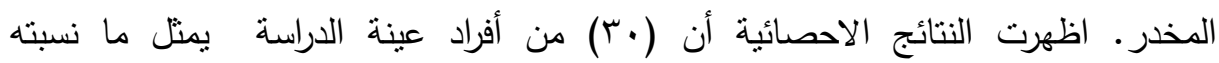
(\% من إجمالي أفراد عينة الدراسة( فثلن فى التوقف عن التعاطى) وهم الفئة الأكثر

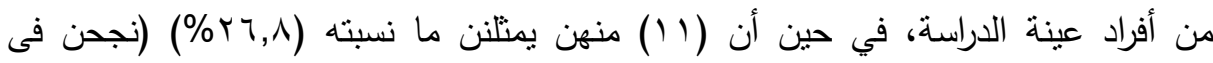

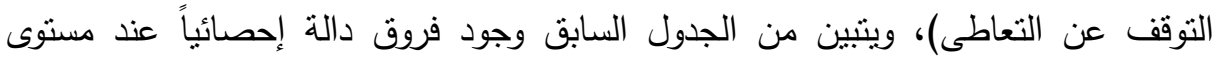
معنوية (0., • ) بين أفراد عينة الدراسة لمتغير التوقف عن التعاطى حيث بلغت قيمة الدلالة

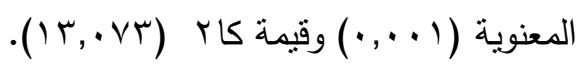

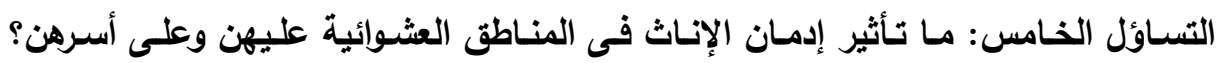

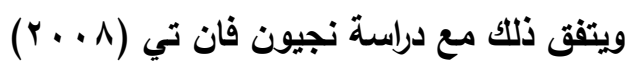

\begin{tabular}{|c|c|c|c|c|c|c|c|c|c|}
\hline \multicolumn{5}{|c|}{ ما هو موقف اسرتك منك ؟ } & \multicolumn{4}{|c|}{ ما هي نظرة الناس اللى حواليكى لكى ؟ } & \multirow[b]{2}{*}{ المتغيرات } \\
\hline المعنوية & St & $\%$ & العدد العد & المتغيرات & المعنوية & كا' & $\%$ & العدد العد & \\
\hline$\cdot, \cdots 1$ & $1 r, q \cdot r$ & rt & 9 & تعاطف & $\cdot, \cdots \wedge$ & $v, \cdot \leq q$ & $r q, r$ & ir & خوف \\
\hline$\cdot, \cdots 1$ & $1 r, q \cdot r$ & rt & 9 & لوم & $\cdot, \cdots 1$ & $r r, \varepsilon r q$ & $M, r$ & 0 & عادى \\
\hline$\cdot, \ldots 1$ & $10, r \leqslant \varepsilon$ & 19,0 & $\wedge$ & الطرد & $\cdot, \cdots 1$ & rr,rq. & $\varepsilon, 9$ & $r$ & احترام \\
\hline$\cdot, \cdots 1$ & $10, r \leqslant \leqslant$ & 19,0 & $\wedge$ & عدم اهتمام & $\cdot, \ldots 1$ & $r r, \Sigma T q$ & $M, r$ & 0 & شفقة \\
\hline \multirow{2}{*}{$\cdot, \cdots 1$} & \multirow{2}{*}{$r \cdot, 01 r$} & \multirow{2}{*}{$1 \leqslant, 7$} & \multirow{2}{*}{7} & \multirow{2}{*}{ 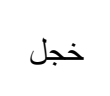 } & $\cdot, r$ & $1,9 \vee 7$ & rq & 17 & سخرية \\
\hline & & & & & $\cdot, \cdots 1$ & $1 \cdot, 107$ & $r \leq, \varepsilon$ & 1. & عدم اهتمام \\
\hline
\end{tabular}

جدول رقم( • 1): التكرارات والنسب المئوية لعينة الدراسة تبعاً لموقف الآخرين منهن

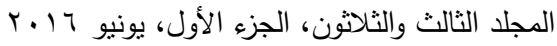


أكدت حالات الدراسة أن أفراد المجتمع ينظرون إلى المتعاطية أما بخوف أو بسخرية

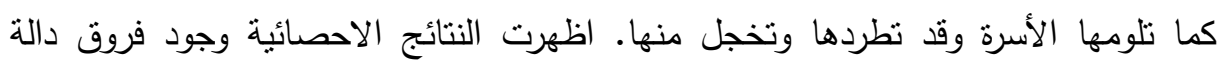

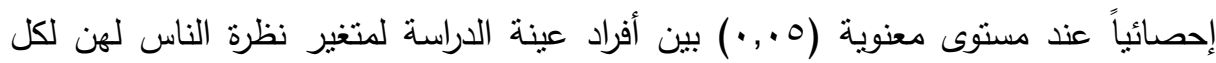

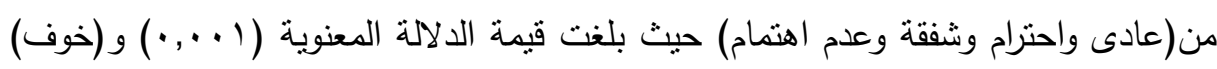

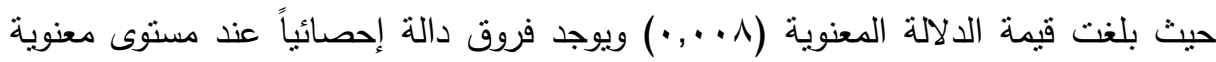
(0., •) بين أفراد عينة الدراسة لمتغير موقف الاصدقاء لكل من (الثفقة ومحاولة المساعدة

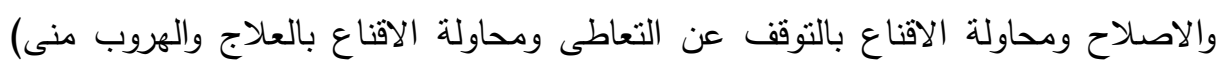

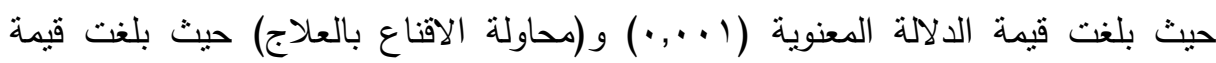

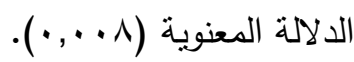
جدول رقم(1 1 ): التكرارات والنسب المئوية لعينة الدراسة تبعاً للتساؤل ايه موقف جيرانك منك؟

\begin{tabular}{|c|c|c|c|c|}
\hline الالالالة المعنويسة & كا & $\%$ & العدد & المتغيرات \\
\hline \multirow{6}{*}{$\cdot, \cdots \varepsilon$} & \multirow{6}{*}{ iv,rq. } & $1 Y, r$ & 0 & خلافات مستمرة \\
\hline & & $I T, Y$ & 0 & تجنب \\
\hline & & 01,0 & $r \varepsilon$ & لامبالاة \\
\hline & & $M, r$ & 0 & مقاطعة \\
\hline & & $\varepsilon, 9$ & $r$ & خوف \\
\hline & & $1 \cdots$ & $\S$ & الإجمالي \\
\hline
\end{tabular}

كما يوجد فروق دالة إحصائياً عند مستوى معنوية (0., +) بين أفراد عينة الدراسة

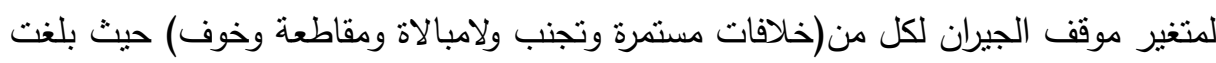

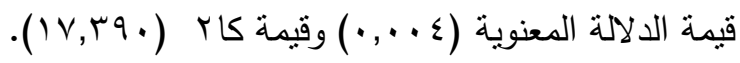


مصطفى إبراهيم عوض وآخرون

جدول رقم( ب ا ): التكرارات والنسب المئوية لمشاكل المنطقة

\begin{tabular}{|c|c|c|c|c|c|c|c|}
\hline \multicolumn{5}{|c|}{ لماذا } & \multicolumn{3}{|c|}{ قفتكرى الحكومة بتحل مشنّاكل الناس } \\
\hline الدعنالة & كا' & $\%$ & العدد & & $\%$ & العدد & المتغيرات \\
\hline$\ddot{i}$ & $\begin{array}{c}r T, T r \\
\varepsilon\end{array}$ & 9,1 & $\varepsilon$ & بالأغنياء فقطط & צ,דז & Y & $\gamma$ \\
\hline$\ddot{1}, \cdots$ & $\begin{array}{r}r 7,07 \\
1\end{array}$ & T & 10 & لا توجد قيمة & $\mid v, 1$ & V & نعم \\
\hline$\cdot, .9$ & $r, 901$ & T & 10 & هنا غير مسموع & 19,0 & $\wedge$ & احيانا \\
\hline & & & & & \multicolumn{2}{|c|}{ \&T, } & is \\
\hline$\cdot, .9$ & $r, 901$ & $r\rceil, \wedge$ & 11 & الحكومة محدودة & \multicolumn{2}{|c|}{$\cdot, \ldots l$} & المعنوية \\
\hline
\end{tabular}

كما أنها تشعر بأن لا قيمة لها فى المجتمع حيث لا نشارك النسبة الأكبر منهن فى

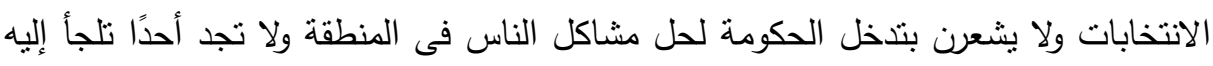

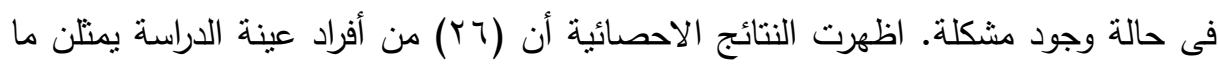

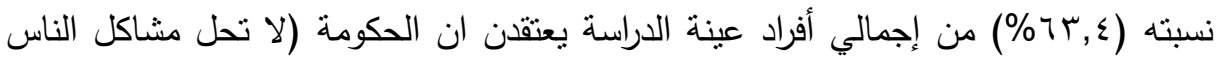

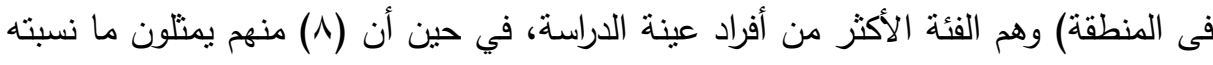

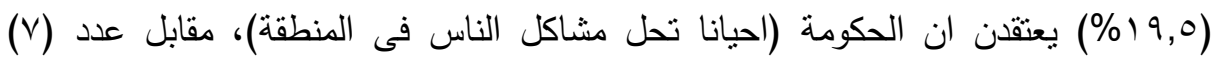

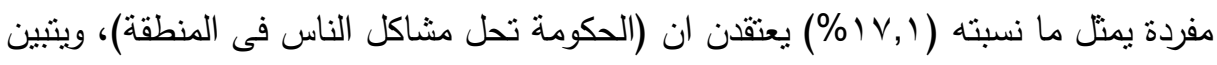

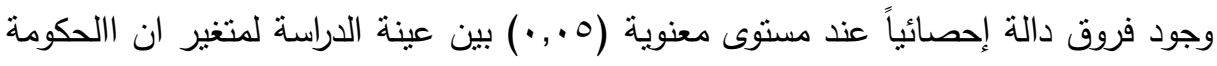

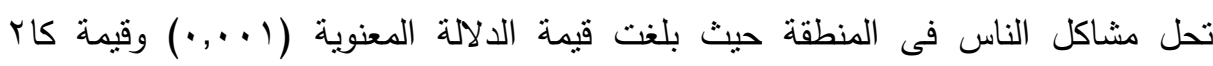

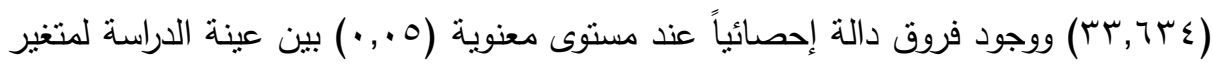
ليه الحكومة لا تهتم بحل المشكلات فى المنطقة لكل من (الاهتمام بالأغنياء فقط والاصلاح ولا توجد قيمة للفرد هنا) حيث بلغت قيمة الدلالة المعنوية (1 . . . ). 
مجلة العلوم البيئية

معهد الدراسات والبحوث البيئية - جامعة عين شمس لهن

جدول رقم(ب 1): التكرارات والنسب المئوية حل مشاكل المنطقة

\begin{tabular}{|c|c|c|c|c|c|c|c|}
\hline \multicolumn{3}{|c|}{ يا ترى انتى لما بيكون عندك مشكلة بتربن } & \multicolumn{4}{|c|}{ تقتكرى الحكومة تعل ايله علثـاس المنطقة } & \multirow[t]{2}{*}{ المتغيرات } \\
\hline$\%$ & العدد & المتغيرات & الالالة المعنوية & s's & $\%$ & العدد & \\
\hline$r \varepsilon, 1$ & $1 \varepsilon$ & أخرى & $\cdot, \Gamma$ & 1,190 & $\Sigma 1,0$ & IV & تتظيم المنطقة \\
\hline$\cdot$ & $\cdot$ & المجلس المحلى &., .9 & $r, 901$ & $7 \pi, \varepsilon$ & ry & مكافحة المخدرات \\
\hline$r, \varepsilon$ & 1 & شخص كبير فى & $\cdot, .9$ & $r, 901$ & 跑 & rq & نوفير الخدمات \\
\hline$r, \Sigma$ & 1 & اى واحد متعلم & $\cdot, \cdots 1$ & $1 \cdot, 907$ & $r \varepsilon, \varepsilon$ & 1. & توفير فرص العمل \\
\hline 71 & ro & لا الجأ لاحد & \multirow{4}{*}{$\cdot, 9$} & \multirow{4}{*}{$\cdot, \cdot r \leq$} & \multirow{4}{*}{$01, r$} & \multirow{4}{*}{ r) } & \multirow{4}{*}{ مكافحة الجرائم } \\
\hline $1 \ldots$ & $\sum 1$ & الإجمالي & & & & & \\
\hline \multicolumn{2}{|c|}{ एव,Y } & rs & & & & & \\
\hline \multicolumn{2}{|c|}{$\cdot, \ldots 1$} & الالالة المعنوية & & & & & \\
\hline
\end{tabular}

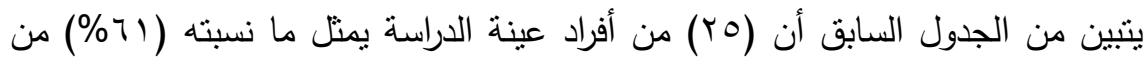

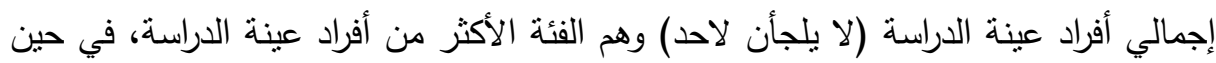

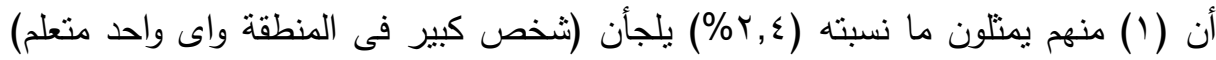

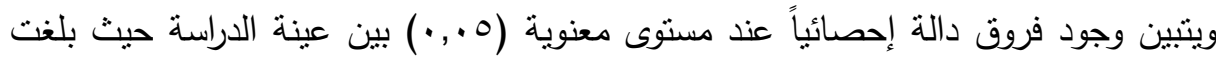

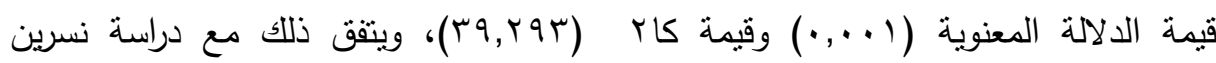

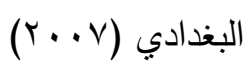


التساؤل السـادس: مـا هى المتغيرات الاجتماعية والنفسية المعاصرة فى المجتمع المصرى

وعلاقتها بإدمان الإناث فى المناطق العشوائية؟

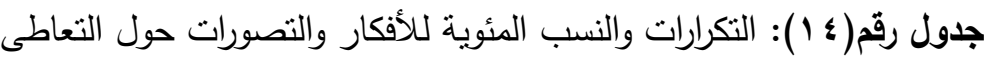

\begin{tabular}{|c|c|c|c|c|c|c|c|c|}
\hline \multirow{2}{*}{ المعنوية } & \multirow{2}{*}{ كا' } & \multicolumn{2}{|c|}{ لا اعرف } & \multicolumn{2}{|c|}{ غير موافق } & \multicolumn{2}{|c|}{ موافق } & \multirow{2}{*}{ الأفكار } \\
\hline & & $\%$ & العدد & $\%$ & العدد & $\%$ & العدد & \\
\hline$\cdot, \ldots$ & $1 ., 010$ & $9, \wedge$ & $\varepsilon$ & $\varepsilon 1,0$ & IV & $\varepsilon \wedge, \wedge$ & r. & تحمل مشاق بتساعد على \\
\hline$\cdot, \ldots)$ & Y0,901 & $K, Y$ & 0 & $\mid v, 1$ & v & $v \cdot, V$ & rq & اللجنسرات تزود ميلها \\
\hline$\cdot, \cdots 1$ & 71,901 & $\varepsilon, q$ & r & $\Lambda \cdot, 0$ & זי & $1 \leqslant, 7$ & 7 & الها تفركر كويس فى الواحدة \\
\hline$\cdot, \cdots)$ & $0 ., 0 \mathrm{VV}$ & $r, \varepsilon$ & 1 & $I Y, Y$ & 0 & $10, \varepsilon$ & ro & المخدرات همومهاعد على \\
\hline$\cdot, \cdots)$ & $Y \uparrow, \wedge .0$ & $9, \wedge$ & $\varepsilon$ & $\leq 7, r$ & 19 & $\varepsilon r, q$ & 11 & وشجاعة المخدات بتخيلها قوية \\
\hline$\cdot, \ldots 1$ & $r V, O r V$ & $9, \wedge$ & $\varepsilon$ & $r \uparrow, \Lambda$ & 11 & צ & ז & خفيف المخدات بتخلى دمها \\
\hline$\cdot, \ldots)$ & $\varepsilon \vee, \varepsilon \wedge \Lambda$ & $\varepsilon, q$ & r & $\uparrow \uparrow, \Lambda$ & 11 & $\uparrow \Lambda, \Gamma$ & rA & 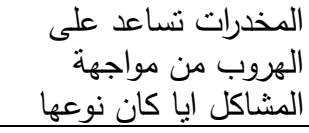 \\
\hline$\cdot, \cdot$, & 19,190 & $\mid v, 1$ & v & rq & 17 & $\varepsilon r, q$ & 11 & الاحخلام تتحقق تصور ان \\
\hline$\cdot, \ldots 1$ & YY,OIY & $1 \leq, 7$ & 1 & $\varepsilon \wedge, \wedge$ & $r$. & M 4,7 & 10 & الادخدرات السماوية لا تحرم \\
\hline
\end{tabular}

اتضح من خلال تتبع الحالات وجود بعض المتغيرات الاجتماعية التى لها علاقة بإدمان الإناث منها ضعف الرقابة الوالدية، التفكل الأسرى، الخلافات المستمرة داخل الأسرة، أصدقاء

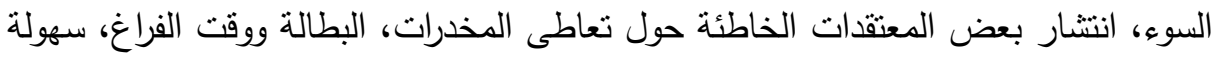
الحصول على المخدر، الغياب الأمنى، التهميش والفقر. اظهرت النتائج الاحصائية وجود فروق دالة إحصائياً عند مستوى معنوية (0., ·) بين عينة الدراسة حيث بلغت قيمة الدلالة

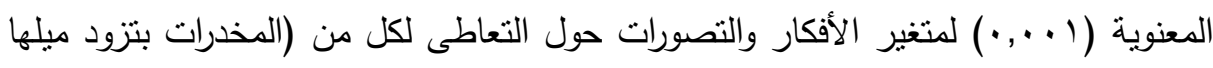
للجنس وتساعدها تفكر كويس فى مشاكلها، وتنساعدها على نسيان همومها، وتخلى دمها 
خفيف، وتساعد على الهروب من مواجهة المشاكل ايا كان نوعها، وتصور ان احلامها تحققت والاديان السماوية لا تحرم المخدرات).

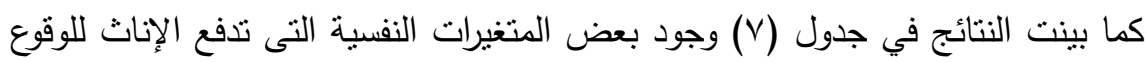
فى دائرة التعاطى، وتلك الهئيات تدعم هذا السلوك، وتضمن له الاستمرار منل التقليد

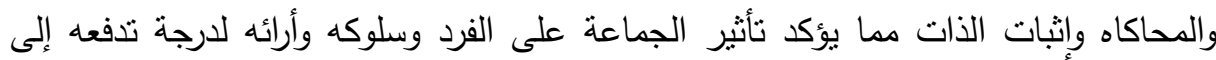

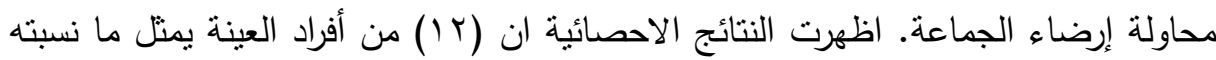

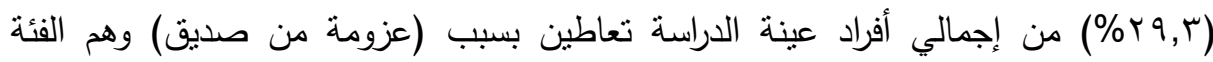

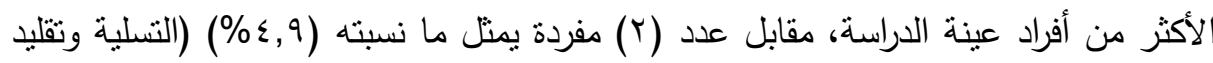

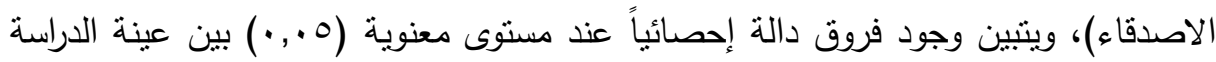
لمتغير سبب التعاطى ويوجد فروق دلالة احصائية حيث بلغت قيمة الدلالة المعنوية ( ( . , •) كما ترتبط بمثيرات المشقة التى تواجهن في حياتهن، مما قد تسهم في دفعهن نحو الوقوع فى دائرة التعاطى والهروب فى عالم التوهان، وهى تتمثل فى : الهروب من المشكلات

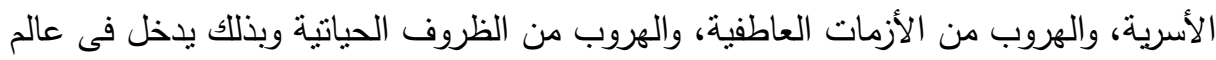

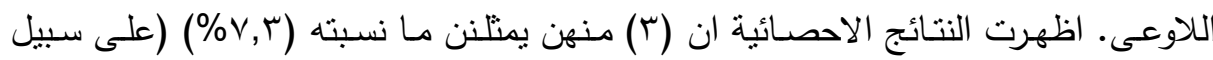

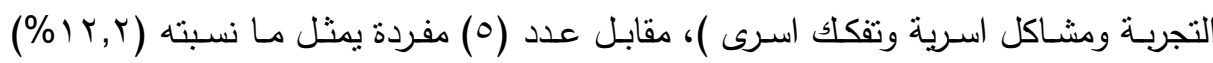

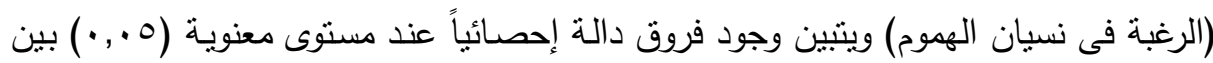
عينة الدراسـة لمتغير سبب التعاطى ويوجد فروق دلالـة احصائية حيث بلغت قيمـة الدلالـة

$$
\text { المعنوية (1 (., (•) }
$$

كما بينت النتائج في جدول (Y) إنعدام المساندة الاجتماعية وعدم وجود حلول أخرى لمان للتغلب على مثـاعر القلق والإحباط، بجانب ضعف الإيمان، وعدم وجود القدوة، مما يدفع الفرد إلى عالم غيبى يتخيل فيه حلوًا لمشاكله ولو لفترة قصيرة، تبعده عن الإحساس بمشاعر

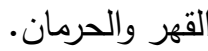

ذلك إلى جانب القدوة السيئة فى الأسرة مثل الأب أو الأخ وخاصة الزوج الذى يدفع

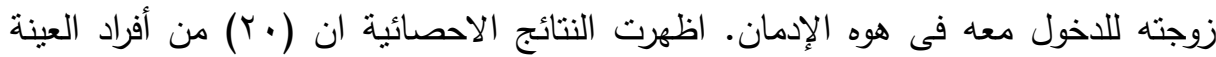


عينة الدراسة تعاطين اول مرة عن طريق (صديقة) وهم الفئة الأكثر من أفراد عينة الدراسة،

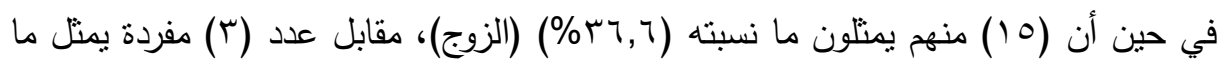

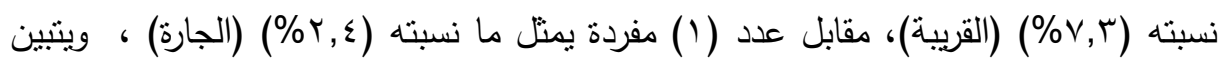

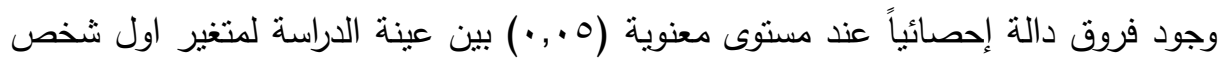

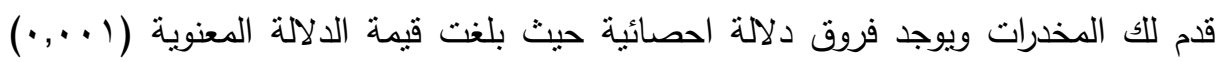

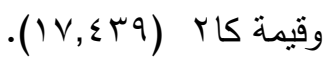
اتفقت الدراسات السابقة التى تتاولت الإدمان والمخدرات والدراسات التى تتاولت المتغيرات الاجتماعية والنفسية مع الدراسة الحالية من التعرف على بعض الدوافع الاجتماعية والنفية للإدمان مثل الرغبة فى نسيان الششاكل والهموم، والثعور بالقلق، والمشاكل

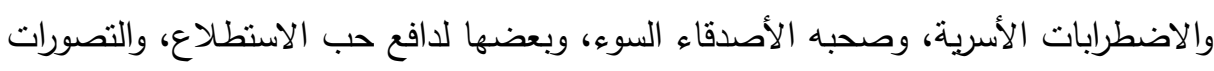

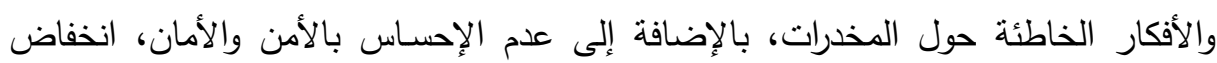
مستوى تعليم الوالدين، وانخفاض مستوى مهنتهما. كما أكدت الدراسات السابقة المدمن ينتمى عادة إلى بيئات دنيا، وأنه يتأثر بالمحيط الاجتماعى: كالعائلة والمدرسة والأقران. كما اتفقت هذه الدراسات مع الدراسة الحالية على أنه يمكن الحد من مشكلة الإدمان من والثن خلال توعيه أفراد منافذ البيع، وحل مشكلات الناس وتفريج همومهم، والوعظ الدينى.

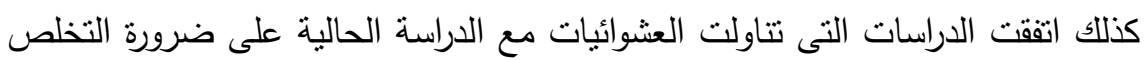

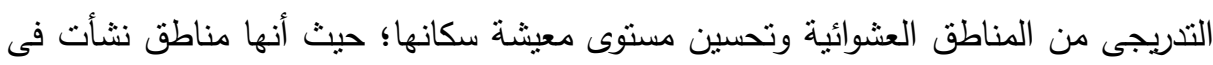

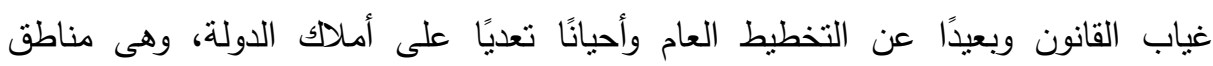

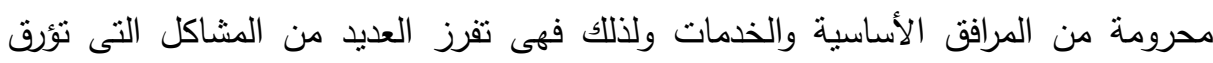
المجتمع وتؤثر سلبًا على أمنه وأمانه، وينتشر بين سكانها الفقر والبطالة والانحراف والجريمة والإدمان وغيرها من المشاكل. 
كما اتفقت الدراسات التى تتاولت جرائم المرأة مع الدراسة الحالية فى أن البنية الأسرية

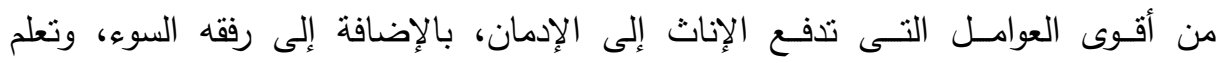

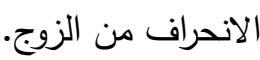

\section{تموسياهي الصراسما}

1- أهمية محافظة الآباء على الاستقرار الأسرى، وكذلك المحافظة على القدوة الصالحة داخل

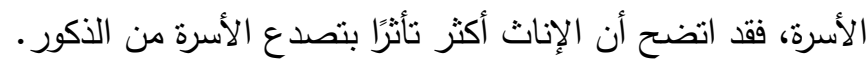

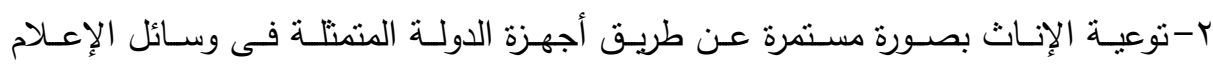

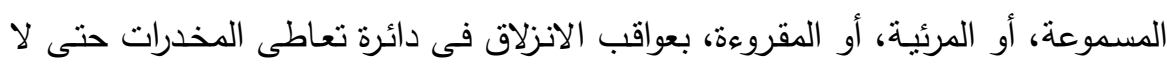
يسهل انقيادها عن طريق محاكاة أو تعليم أحد أفراد عائلتها.

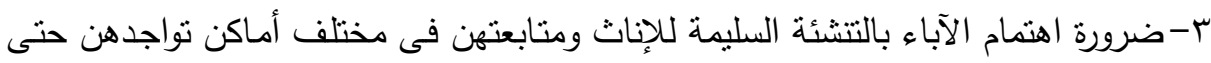

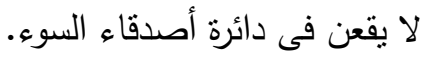
ع-ضرورة مكافحة الأماكن التى يتم فيها توزيع وتعاطى المخدرات حيث أنبتت الدراسة انتشار

$$
\text { توزيع وبيع المخدرات فى المناطق العشوائية. }
$$

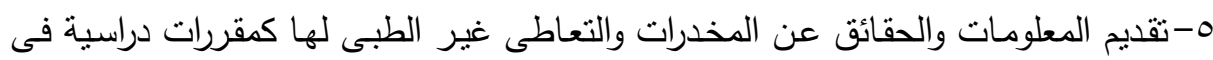

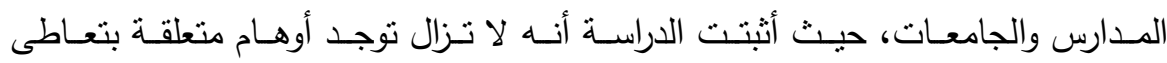

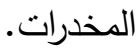
צ-أهمية دراسـة الهناطق العشوائية والأحياء الثعبية، وتحليل بناءهـا التاريخي للوقوف على ثقافتهم وتقديم تقسير ثقافى للعديد من الظواهر التى من أهمها ثقافة المخدرات، مما يتيح اتساعًا واضحًا لمفهوم المناطق العشوائية التى تختلف من حيث الفئ التاريخ والظروف الطارئة والذى يؤدى بدوره إلى ظهور مشكلات اجتماعية أخرى بهذه المناطق فى حاجة أى جهود بحثيه قادمة. V-ضرورة تفعيل الدور المدنى والحكومى فى تغيير الأنماط السلبية فى المجتمعات العشوائية.

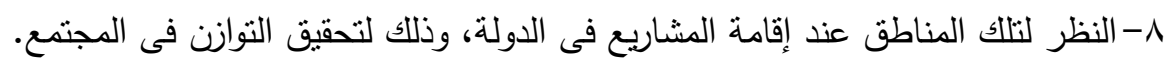




$$
\begin{aligned}
& \text { exlall } \\
& \text { القانون المصرى، قانون التخطيط العمرانى لعام ra19 ـ. } \\
& \text { جابر عبدالحميد جابر وعـلاء الدين كفافى(991 (1): معجم علم النفس والطب النفسى، دار }
\end{aligned}
$$

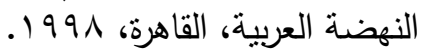

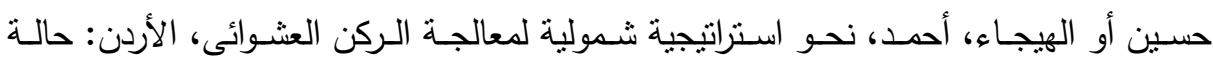

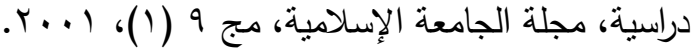

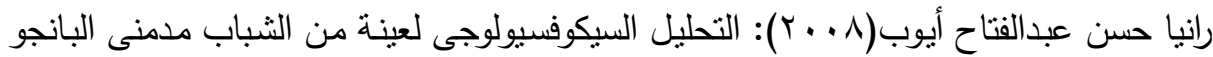

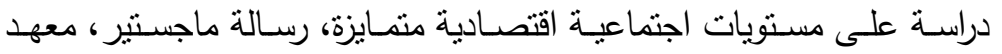

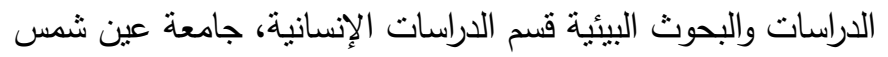

$$
\begin{aligned}
& \text { فاروق سيد عبدالسلام(9VV (1): سيكولوجية الإدمان، عالم الكتب، القاهرة }
\end{aligned}
$$

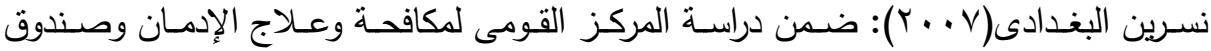

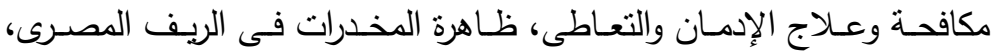

$$
\begin{aligned}
& \text { المركز القومى للبحوث الإديان والتعاطية والجنائية }
\end{aligned}
$$

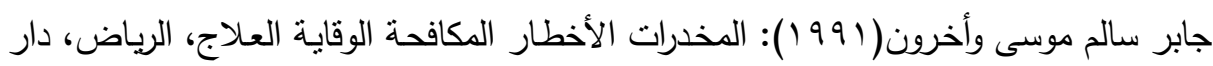

$$
\begin{aligned}
& \text { المريخ } \\
& \text { عادل الدمرداش(ب } 91 \text { ()): الإدمان مظاهره وعلاجه، عالم المعرفة، الكويت } \\
& \text { السبد منولى العشماوى(ب99 (1)): الجواب الاجتماعية لظاهرة الإدمان، المركز العربى للاراسات }
\end{aligned}
$$

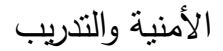

Nguyen, Van T.. Drug abuse among young adults in Vietnam: The influence of family, peers and society - Peoquest Dissertations and Theses 2008. Section 2502 Part 0452, 188 pages; (Ph.D. dissertation). United States- Texas: The University of Texas at Arlington; 2008. Publication Number: AAT 3339265.

Korotkikh, Marina - Risk factors for marijuana use among Russian and Canadian adolescents: A comparative analysis- Proquest Dissertations and Theses 2007. Section 1141, Part 0626, 138 pages; (M.A. dissertation). Canada: University of

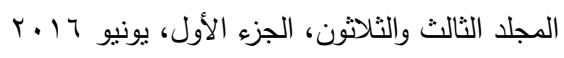


Waterloo (Canada); 2007. Publication Number: AAT MR36426.

\title{
CONTEMPORARY SOCIAL AND PSYCHOLOGICAL VARIABLES AND THEIR RELATIONSHIP WITH THE SPREAD OF ADDICTION PHENOMENON
} AMONG FEMALES IN THE SLUMS

Awad, M. I. ${ }^{(1)}$; Hani, A. F. ${ }^{(1)}$ and Ghali, Lorna, A. ${ }^{(2)}$

1) Institute of Environmental Studies and Research, Ain Shams University 2) The National Council for Drug Control and Treatment

\begin{abstract}
This study aims at identifying the contemporary social and psychological variables such as: the social standard, the family circumstances, education, ecological environment, escaping from problems and tension and feeling inferior, and their relationship with the spread of addiction phenomenon among females in the slums, in addition to identifying the suffering of the habitants in the slums and the stages of falling in addiction.

The study uses the descriptive method. Data was collected through personal meeting and a questionnaire. The sample consists of (41) females who live in the slums. Some theories are used such as: The functional theory, which explains that addiction is the failure of the addict to play his role and that addiction is a delinquent behavior that opposes all the common things in the social system. In addition to the theory of social learning, which explains addiction as an educated behavior, resulted from joining a group of addicts. The results indicate a significant relationship between the contemporary social and psychological variables 290

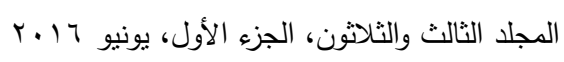


such as: family disintegration, bad friends, the spread of some wrong beliefs about addiction, poverty, escaping from problems and life circumstances and the addiction of women in the slums. Some of the recommendations of the study are:

- The importance of keeping the stability of the family and the good example inside the family as the results show that females are affected with family disintegration more than males.

- The importance of guiding females through media about the consequences of addiction in order not to be easily led through imitating or following a member of the family.

- The importance of studying the slums and including them in the projects of the state. 